IZA DP No. 9357

Income Guarantees and Borrowing in Risky

Environments: Evidence from India's

Rural Employment Guarantee Scheme

Clive Bell

Abhiroop Mukhopadhyay

September 2015 


\title{
Income Guarantees and Borrowing in Risky Environments: Evidence from India's Rural Employment Guarantee Scheme
}

\author{
Clive Bell \\ University of Heidelberg \\ and Chr. Michelsen Institute \\ Abhiroop Mukhopadhyay \\ Indian Statistical Institute \\ and IZA \\ Discussion Paper No. 9357 \\ September 2015 \\ IZA \\ P.O. Box 7240 \\ 53072 Bonn \\ Germany \\ Phone: +49-228-3894-0 \\ Fax: +49-228-3894-180 \\ E-mail: iza@iza.org
}

Any opinions expressed here are those of the author(s) and not those of IZA. Research published in this series may include views on policy, but the institute itself takes no institutional policy positions. The IZA research network is committed to the IZA Guiding Principles of Research Integrity.

The Institute for the Study of Labor (IZA) in Bonn is a local and virtual international research center and a place of communication between science, politics and business. IZA is an independent nonprofit organization supported by Deutsche Post Foundation. The center is associated with the University of Bonn and offers a stimulating research environment through its international network, workshops and conferences, data service, project support, research visits and doctoral program. IZA engages in (i) original and internationally competitive research in all fields of labor economics, (ii) development of policy concepts, and (iii) dissemination of research results and concepts to the interested public.

IZA Discussion Papers often represent preliminary work and are circulated to encourage discussion. Citation of such a paper should account for its provisional character. A revised version may be available directly from the author. 


\section{ABSTRACT}

\section{Income Guarantees and Borrowing in Risky Environments: Evidence from India's Rural Employment Guarantee Scheme*}

This paper investigates the effects of an income guarantee on borrowing to smooth consumption and finance cultivation in a risky setting with marked seasonality. A threeseason, infinite-horizon theoretical model is developed and analyzed. The insights yielded by the model are then used to interpret results from an empirical analysis which uses data on a sample of households in a semi-arid region of Odisha state. The potential endogeneity of borrowing and NREGS earnings is instrumented using the female reservation for local elections. An additional day of work at the regulated wage reduces the estimated amount borrowed for consumption by about half the wage. For the financing of working capital, it increases such borrowing by an estimated amount that is almost twice as large as the wage. NREGS is therefore effectively a substitute for borrowing if a household does not cultivate, but a complement if it does so.

JEL Classification: J3, Q12, Q38

Keywords: income guarantee, borrowing, NREGS, India

Corresponding author:

Abhiroop Mukhopadhyay

B 10

Indian Statistical Institute

7 S.J.S. Sansanwal Marg

New Delhi 110016

India

E-mail: abhiroop@isid.ac.in

\footnotetext{
* Earlier versions of this paper were presented at CMI and the Delhi School of Economics. We are particularly indebted to Magnus Hatlebakk for numerous and valuable discussions. All responsibility for any remaining errors of formulation and analysis is ours alone. The study received financial support from the Research Council of Norway via the INDNOR program. The opinions expressed herein do not necessarily represent those of the institution.
} 


\section{Introduction}

Providing social protection when private action has failed is widely accepted to be an important function of government. An essential element of any such general scheme is ensuring that households do not suffer acute want when current income is low, whether the cause be seasonal, the weather, illness or death in the family, or a bad harvest. In principle, there are ways to deal with these hazards without public intervention. Households could set aside precautionary savings, or rely on the family network, or take a loan - if credit is available. In vast tracts of the semi-arid tropics, however, most of the population is poor and lives from hand to mouth; natural shocks are strong and spatially correlated; and, unsurprisingly, credit markets do not function particularly well.

This vulnerability motivates proposals to provide publicly guaranteed incomes. The private response that concerns us in this paper is households' borrowing behaviour in risky settings, where we distinguish between the desire for a smooth path of consumption and, for cultivating households, the need to finance working capital. Treating an income guarantee as an increase in the certain component of income, we analyse its effects on borrowing at various points over the course of a full period as the associated random component of income is realised.

The structure developed for this purpose comprises three seasons in each period. Households may borrow in seasons 1 and 2. Cultivation takes place in season 2. Those households that cultivate choose how much working capital to employ, a decision that is combined with how much to borrow in that season. All outstanding debt is due for repayment in season 3, when the harvest is brought in. Those that meet their obligations remain in good standing and may borrow in the next period. Those that choose to default are shut out of the credit market for good thereafter, a penalty that all rationally anticipate and one which thus imposes a measure of discipline on their choices of how much to borrow in earlier seasons. Income is stochastic, each season 
having its own particular distribution function.

This structure extends the well-known 'lean season-peak season' model (see Bardhan (1983) for an early application to labour-tying), which is too inflexible for our purposes. The introduction of a third season accommodates the prevailing seasonal pattern of activities, morbidity and transactions more sensitively than the two-season model, which operates in the present context rather like a procrustean bed. To elaborate, in monsoonal agriculture households have to cope with two kinds of shocks, namely, those that affect its members' health and those that affect their employment and output, each of which has a definite seasonal pattern. Morbidity starts to rise in April, reaches its peak in the monsoonal months, and retreats again in October. April and May, however, belong to the lean season for work, whereas land preparation and sowing are normally under way in earnest by the end of June - if the rains come on time. The main harvest season runs from December to the end of January. The typical two-season model forces into the second season the borrowing decisions for financing cultivation and the bouts of illness that occur in the monsoon with the later decision of whether to default on loans when the harvest has been brought in - if the latter option is allowed. The separation of what are intrinsically two different kinds of decisions into separate second and third seasons enables us to analyse more precisely, within a unified framework, consumptionsmoothing and the financing of working capital over this entire cycle of activities and natural shocks.

The combination of these features marks out the structure from other contributions in which seasonality plays a central role. Bell et al. (1997) analyse the financing of cultivation when there is no consumption in the first season and rational default is an option in the second. Basu (2013) concentrates on agricultural labourers, who are assumed to have some probability of securing consumption in both seasons by tying themselves to an employer for the whole year, with working on a public project in the first season and casual work at a stochastic wage at harvest time as the alternative. Borrowing is ruled out. The same restriction applies in Raghunathan and Fields (2014), 
who analyse competitive wage-determination in a setting without risk. Gehrke (2014) is concerned only with cultivating households: consumption can be spread over both seasons, but default is (implicitly) ruled out.

The chief results are as follows. The size of a consumption loan in either season is decreasing in the size of the contemporaneous income payment, but payments in other seasons have mixed effects. Borrowing in season 1 is increasing in payments in season 2, which are assumed to be known with certainty. Borrowing in season 2 is increasing in borrowing in season 1 (which is a state variable in season 2), however, so that an increase in payments in season 1 can outweigh the effect of an increase in those in season 2, causing the level of borrowing in the latter to fall. The effects of an increase in payments in season 3 on borrowing in the preceding seasons are ambiguous in general. If the probability of default and its sensitivity to changes in payments in season 3 are sufficiently small, the desire for a smooth path of consumption will win out, and borrowing in seasons 1 and 2 will rise. If the household cultivates, borrowing in season 2 can arise from the need to finance working capital as well as current consumption, whereby a single budget constraint prevents drawing a clear line between them. In contrast, there is a clear distinction between the level of borrowing and that of outlays on working capital. Under certain plausible restrictions on preferences and the agricultural technology, both these levels are increasing in payments received in both seasons 1 and 2 .

With these results in mind, we analyse the effects of India's National Rural Employment Guarantee Scheme (hereinafter NREGS) on households' borrowing behaviour. Under this scheme, all rural households have the right to obtain up to 100 days a year of employment on public projects at a fairly generous regulated wage. It therefore provides those that have, at any time, at least one able-bodied adult member the option of earning a guaranteed amount of income.

We use the insights from the theoretical model and conduct an empirical analysis 
using cross-sectional data from 279 households drawn from 30 villages in a semi-arid and backward part of Odisha, an eastern state of India. We evaluate the impact of both participation, and the total number of days worked, in NREGS on borrowing for the following purposes: purchasing food, meeting the costs of illness and death, and funding working capital for cultivation. We classify the first and second as consumption loans and the latter as production loans. The empirical challenge is to account for unobserved cross-sectional differences among households that may covary with borrowing as well as NREGS participation, thus confounding the analysis. To deal with this problem, we exploit a legal restriction on elections to the Gram Panchayat, the lowest level of government in India's federal system and the one responsible for administering NREGS. The head of this body is called the Sarpanch. In some villages, the position is reserved for women, and this reservation is applied randomly across villages. We instrument a household's participation in NREGS by an indicator variable for whether there was a gender reservation in its village. This idea is motivated by the finding that, in the neighbouring state of Andhra Pradesh, the implementation of NREGS worsened in the first two years of newly elected female Sarpanches' tenure (Afridi et al., 2014).

This finding is confirmed by our empirical analysis. We find that the probability of a household doing NREGS work is lower if the village's Sarpanch is female. According to our instrumental variables (IV) estimates, working in NREGS decreases the probability of borrowing for consumption, but increases that for production. For those who borrow, one more day of NREGS work lowers the size of a consumption loan by almost half of the daily earnings from NREGS and raises the size of a production loan by a little more than twice those earnings. These results are in line with the model's results. Not all of the model's predictions for each season can be tested using our data, but two of them are borne out: the impact of NREGS on borrowing in season 1 is negative, in season 2 it is positive.

The validity of our findings would be undermined by a failure of the exclusion restriction. If Sarpanches also affect outcomes though their administration of other policies, 
our results would be confounded. We conduct sensitivity analyses to assuage fears on this count. Our results are robust to the inclusion of the total expenditure on other schemes that the Sarpanch administers. The same holds for the other big policy intervention in this part of India, namely, the provision of all-weather roads.

This paper contributes to a growing literature on the impact of NREGS on outcomes at the household level. The most cited papers have largely focused on labour market outcomes and households' per capita consumption expenditure (Azam, 2014; Imbert and Papp, 2015; Klonner and Oldiges, 2014; Zimmerman, 2014). These papers use various National Sample Survey data sets. The results seem to depend on the exact identification method used. The impact of NREGS on credit has also been explored using smaller village samples. Dey and Imai (2014) and Saraswat (2011) contend that NREGS participation improves households' creditworthiness, so that borrowing rises. Their arguments depend on an implicit model in which borrowing is constrained by collateral and there are no production loans. Collateral plays no role in our model, but an increase in borrowing can stem from the desire to smooth consumption, depending on the timing of NREGS payments. Raghunathan and Hari (2014) argue that additional income from NREGS provides insurance in high-risk environments and relaxes credit constraints, so promoting farmers' adoption of riskier but higher productivity crops. None of these papers attempts to investigate the relationship between borrowing and the seasonal pattern of shocks, cultivation activities and NREGS payments over the year.

The paper is structured as follows. The variant of the model in which households do not cultivate, and so borrow only to smooth consumption, is developed and analysed in Section 2. Section 3 extends the model to cultivating households. Section 4 describes the data set. Section 5 lays out the empirical model and describes our identification strategy (see Section 5.1). We report and discuss our main results in Section 6, followed by an analysis of seasonality and robustness checks. The chief conclusions are drawn together in Section 7. 


\section{The Basic Model: Consumption-smoothing}

Each full period $\tau$ comprises three seasons, denoted by $t(=1,2,3)$. Let income in season $t$ of period $\tau$ comprise a fixed component $\eta_{t}(\tau)$ and a random component denoted by the stationary variate $\Xi_{t}(\tau)$, with $\operatorname{CDF} F_{t}\left(\xi_{t}(\tau)\right)$, whose support is $\left[\xi_{t}^{1}, \xi_{t}^{2}\right]$ in all periods. Income cannot be saved for use in subsequent seasons, but it can be augmented with loans in each of seasons 1 and $2 .^{1}$ All loans have a maturity of one season, but a loan taken in season 1 may be effectively rolled over, wholly or in part, by borrowing again in season 2 . The whole outstanding amount at the end of season 3 must, however, be repaid out of current income, or the borrower will be in default. ${ }^{2}$ A borrower in good standing at the start of period $\tau$ will therefore have the following levels of consumption in each of the three seasons, respectively:

$$
\begin{gathered}
c_{1}(\tau)=\xi_{1}(\tau)+\eta_{1}(\tau)+K_{1}(\tau), \\
c_{2}(\tau)=\xi_{2}(\tau)+\eta_{2}(\tau)+K_{2}(\tau)-R(\tau) K_{1}(\tau),
\end{gathered}
$$

and

$$
c_{3}(\tau)=\xi_{3}(\tau)+\eta_{3}(\tau)-R(\tau) K_{2}(\tau) \text { if he repays, } c_{3}(\tau)=\xi_{3}(\tau)+\eta_{3}(\tau) \text { otherwise }
$$

where $r(\tau)$ is the rate of interest in period $\tau, R(\tau) \equiv 1+r(\tau)$ and $K_{t}(\tau) \geq 0$ is the amount borrowed in season $t$ of period $\tau$.

An agent ${ }^{3}$ who does not borrow in period $\tau$, whether by choice or because he had defaulted in some earlier period, will obtain the (random) consumption vector

$$
\mathbf{c}^{a}(\tau) \equiv\left(\xi_{1}(\tau)+\eta_{1}(\tau), \xi_{2}(\tau)+\eta_{2}(\tau), \xi_{3}(\tau)+\eta_{3}(\tau)\right)
$$

\footnotetext{
${ }^{1}$ If a household receives a modest windfall, it may well be pestered by relatives who hear about it; and even if it can fend them off, it will hardly have the knowledge and resources to enter the credit market as a lender.

${ }^{2}$ For simplicity, renegotiation is ruled out.

${ }^{3}$ Fewer than one household in 20 of the sample has a female head.
} 
where $\xi_{t}(\tau)$ is a realised value of $\Xi_{t}(\tau)$. Let an agent in default at the start of period $\tau$ place the value $V^{a}(\tau)$ on the stochastic stream $\left(\mathbf{c}^{a}(\tau), \mathbf{c}^{a}(\tau+1), \mathbf{c}^{a}(\tau+2), \ldots\right)$.

An agent in good standing at the start of period $\tau$ will choose an ex ante optimal borrowing plan in that period, taking into account a crucial decision to be made at the close of season 3, when any outstanding obligations in the current period fall due, namely, whether to meet them. If he defaults, he will obtain the continuation value $V^{a}(\tau+1)$. Let the value of the optimal plan, as viewed ex ante at the very start of period $\tau$, when none of $\left(\xi_{1}(\tau), \xi_{2}(\tau), \xi_{3}(\tau)\right)$ is known, with possible revisions to the plan contingent on them, be denoted by $V^{0}(\tau)$.

In order that the setting be a stationary one, we make the following assumptions. Assumption 1. Let $\eta_{t}(\tau+k)=\eta_{t}(\tau)$ and $R(\tau+k)=R(\tau) \forall k \geq 1$, and let the variates $\Xi_{t}(\tau), t=1,2,3$ be stationary and serially independent within and across periods.

In virtue of Assumption 1, $V^{0}(\tau)$ and $V^{a}(\tau)$ are independent of $\tau$, and it suffices to consider the decisions of an agent in good standing at the start of period 0 . In this stationary setting, the period variable $\tau$ may be dropped without ambiguity in what follows. The argument proceeds by backwards induction.

\section{$2.1 \quad$ Season 3}

At the close of season 3, the realisation $\xi_{3}$ is known and the amount due is $R K_{2}$. The only decision is whether to repay and so remain in good standing, or to default and so obtain the future income stream that yields $V^{a}$. Let the agent's preferences over lotteries in each season be representable by the increasing, strictly concave, twicedifferentiable function $u\left(c_{t}\right)$. Denote by $\xi_{3}^{d}$ that value of $\xi_{t}$ such that the agent is indifferent between repaying and defaulting. Then, recalling (3), $\xi_{3}^{d}$ satisfies the condition

$$
u\left(\xi_{3}^{d}+\eta_{3}-R K_{2}\right)+\delta V^{0}=u\left(\xi_{3}^{d}+\eta_{3}\right)+\delta V^{a},
$$


where $\delta$ is the inter-period discount factor. It is seen from the assumptions on $u(\cdot)$ that $\xi_{3}^{d}$ is unique. We may therefore write $\xi_{3}^{d}=\xi_{3}^{d}\left(\eta_{3}, K_{2}, \delta\left(V^{0}-V^{a}\right)\right)$, where the term $\delta\left(V^{0}-V^{a}\right)$ measures the penalty attached to a default. Whatever be his ex ante intentions, the agent knows that it is condition (4) that will govern his actions when the time comes: if the realization $\xi_{3}<\xi_{3}^{d}$, he will default, and repay otherwise.

We turn to comparative statics. We begin by assuming that any changes in the riskfree components of income, $\left(\eta_{1}, \eta_{2}, \eta_{3}\right)$, are strictly temporary. That is to say, they occur only in the period in question, and the status quo ante holds in all subsequent periods, so that $V^{0}$ and $V^{a}$ do not change. The case where the changes are permanent are treated in the Appendix. Although $V^{0}$ and $V^{a}$ now vary, the results are qualitatively the same.

Inspection of (4) reveals that if $\xi_{3}^{d}>\xi_{3}^{1}$, then the default value $\xi_{3}^{d}$ and $\eta_{3}$ move in opposite directions, with $\partial \xi_{3}^{d} / \partial \eta_{3}=-1$. Also,

$$
\partial \xi_{3}^{d} / \partial K_{2}=\frac{R u^{\prime}\left(\xi_{3}^{d}+\eta_{3}-R K_{2}\right)}{u^{\prime}\left(\xi_{3}^{d}+\eta_{3}-R K_{2}\right)-u^{\prime}\left(\xi_{3}^{d}+\eta_{3}\right)}>1
$$

At this stage, an increase in the fixed component $\eta_{3}$ induces a lower probability of default, whereas a larger repayment obligation, which could have arisen earlier in the certain anticipation of a larger $\eta_{3}$, increases that probability.

\subsection{Season 2}

At the start of season $2, K_{1}$ is known from the previous season. It is assumed that the decision about $K_{2}$ can be deferred until the realisation $\xi_{2}$ has been revealed. At this point, therefore, $c_{2}$ is certain and only $\xi_{3}$ is unknown. Let the agent's preferences over $c_{2}$ and the consumption lottery in period 3 , with its possible continuations, be 
represented by

$$
\begin{aligned}
V_{2}\left(\xi_{2}\right) & =u\left(c_{2}\right)+\beta\left[\int_{\xi_{3}^{1}}^{\xi_{3}^{d}} u\left(\xi_{3}+\eta_{3}\right) d F_{3}+\int_{\xi_{3}^{d}}^{\xi_{3}^{2}} u\left(\xi_{3}+\eta_{3}-R K_{2}\right) d F_{3}\right] \\
& +\beta \delta \cdot\left[p V^{0}-(1-p) V^{a}\right],
\end{aligned}
$$

where $\beta$ is the inter-seasonal discount factor and $p=1-F_{3}\left(\xi_{3}^{d}\right)$ is the probability that the outstanding loan will be repaid. It should be noted that if $\xi_{3}^{d}<\xi_{3}^{1}$, the probability of default will be zero, the first integral in brackets will vanish, the lower limit of integration in the second term will be $\xi_{2}^{1}$, and the term involving $V^{a}$ will also vanish.

The agent's decision problem at this stage is to choose $K_{2}$ so as to maximise $V_{2}$ subject to (2) and (4). In view of the latter condition, which expresses the optimality of $\xi_{3}^{d}$ given $K_{2}$, the f.o.c. reduces to

$$
u^{\prime}\left(\xi_{2}+\eta_{2}+K_{2}-R K_{1}\right)-\beta R \int_{\xi_{3}^{d}}^{\xi_{3}^{2}} u^{\prime}\left(\xi_{3}+\eta_{3}-R K_{2}\right) d F_{3} \leq 0, K_{2} \geq 0
$$

which implicitly defines the optimum as a function of the quantities $\xi_{2}, \eta_{2}, \eta_{3}$ and $K_{1}$ : namely, $K_{2}^{0}=K_{2}^{0}\left(\xi_{2}, \eta_{2}, \eta_{3}, K_{1}\right)$, given the fixed penalty term $\delta\left(V^{0}-V^{a}\right)$.

Assuming an interior solution w.r.t. $K_{2}$, and that $\xi_{3}^{d}>\xi_{3}^{1}$, total differentiation of (6) and some rearrangement yield the following results:

$$
\begin{gathered}
\frac{\partial K_{2}^{0}}{\partial \eta_{2}}=\frac{\partial K_{2}^{0}}{\partial \xi_{2}}=-\frac{u_{2}^{\prime \prime}}{\partial^{2} V_{2} / \partial K_{2}^{2}}<0 \\
\frac{\partial K_{2}^{0}}{\partial \eta_{3}}=\frac{\beta R\left(\int_{\xi_{3}^{d}}^{\xi_{3}^{2}} u^{\prime \prime}\left(\xi_{3}+\eta_{3}-R K_{2}\right) d F_{3}-u^{\prime}\left(\xi_{3}+\eta_{3}-R K_{2}\right) F_{3}^{\prime}\left(\xi_{3}^{d}\right) \cdot\left(\partial \xi_{3}^{d} / \partial \eta_{3}\right)\right)}{R \cdot \partial^{2} V_{2} / \partial K_{2}^{2}}
\end{gathered}
$$

and

$$
\frac{\partial K_{2}^{0}}{\partial K_{1}}=\frac{R u_{2}^{\prime \prime}}{\partial^{2} V_{2} / \partial K_{2}^{2}}>0
$$


where

$\frac{\partial^{2} V_{2}}{\partial K_{2}^{2}}=u_{2}^{\prime \prime}+\beta R^{2}\left(\int_{\xi_{3}^{d}}^{\xi_{3}^{2}} u^{\prime \prime}\left(\xi_{3}+\eta_{3}-R K_{2}\right) d F_{3}+u^{\prime}\left(\xi_{3}^{d}+\eta_{3}-R K_{2}\right) F^{\prime}\left(\xi_{3}^{d}\right) \cdot\left(\partial \xi_{3}^{d} / \partial K_{2}\right)\right)<0$

at the optimum. The sign of $\partial K_{2}^{0} / \partial \eta_{3}$ is ambiguous; for the two terms in the numerator have opposite signs. It is seen that if both the probability of default and the corresponding density at $\xi_{3}^{d}$, i.e. $F_{3}^{\prime}\left(\xi_{3}^{d}\right)$, are sufficiently small, then the corresponding effect of a change in $\eta_{3}$ on the probability of default will not outweigh the strict concavity of $u$; so that the pure consumption-smoothing effect will dominate and $K_{2}^{0}$ will indeed be increasing in $\eta_{3}$.

In order to grasp the intuition for these results, it is helpful to begin by considering the special case wherein default does not occur, so that the only effect at work arises from the desire to smooth consumption over the whole of the current period. The second term in parentheses on the r.h.s. of (10) vanishes and the lower limit of integration in the first is $\xi_{3}^{1}$. A small increase in income at the time of decision in period 2 will induce the agent to borrow less, and so increase the excess of the certain component of income over loan repayments, and hence the level of consumption for any given realisation $\xi_{3}$ in period 3. Likewise, an increase in the certain component of income in period 3 will induce him to borrow a bit more, but less than the said increase, in period 2, so as to enjoy that much more consumption immediately in period 2. An increase in the amount borrowed in period 1 will put an extra burden on the certain component of income in period 2 , and so induce an increase in borrowing, but by less than $R$ times that amount in period 2, so as to increase the net certain component of consumption in period 2, while not displacing the whole of the burden of adjustment onto consumption in period 3 (compare (9) and (10)).

As noted above, if the possibility of default is actually in play, an increase in $\eta_{3}$ will, cet. par., reduce $\xi_{3}^{d}$ by the same amount, and hence also the probability of default. Since $u$ is strictly concave, the resulting increase in $c_{3}$ for any given $\xi_{3}$ will induce the 
agent to exploit this particular margin by increasing $K_{2}$; but in so doing, the increase in $\eta_{3}$ will also extend the lower end of the range of values of $\xi_{3}$ in which repayments are made. It is in this range that the austerity entailed by repayment pinches hardest, and any relief through $\eta_{3}$ will therefore make borrowing in season 2 somewhat less attractive. Yet this particular effect is dominated at the point of decision in season 2 where changes in $\eta_{2}, \xi_{2}$ and $R K_{1}$ are concerned, because $u_{2}^{\prime \prime}$ comes into the reckoning, both directly and through $\partial^{2} V_{2} / \partial K_{2}^{2}$, which is negative at the optimum. For such changes, the desire to smooth consumption will win out.

\subsection{Season 1}

At the very beginning of the whole sequence at the start of season 1, it is likewise assumed that the decision concerning $K_{1}$ can be deferred until $\xi_{1}$ has been revealed. Both $\xi_{2}$ and $\xi_{3}$ are, of course, still unknown at this stage. Analogously to $V_{2}$, we have

$$
V_{1}\left(\xi_{1}\right)=u\left(\xi_{1}+\eta_{1}+K_{1}\right)+\beta \int_{\xi_{2}^{1}}^{\xi_{2}^{2}} V_{2}\left(\xi_{2}\right) d F_{2} \equiv u_{1}+\beta E_{\xi_{2}}\left[V_{2}\left(\xi_{2}\right)\right] .
$$

The agent's corresponding decision problem is to choose $K_{1}$ so as to maximise $V_{1}$ anticipating the optimal choice of $K_{2}$ in period 2 once $\xi_{2}$ has been realised and noting condition (4). Recalling (6), which characterises the optimal choice of $K_{2}$ for each and every realisation of $\xi_{2}$, the f.o.c. reduces to

$$
u^{\prime}\left(\xi_{1}+\eta_{1}+K_{1}\right)-\beta R \cdot \int_{\xi_{2}^{1}}^{\xi_{2}^{2}} u^{\prime}\left(\xi_{2}+\eta_{2}+K_{2}^{0}-R K_{1}\right) d F_{2} \leq 0, K_{1} \geq 0 .
$$

Differentiating totally and using $(7)-(9)$, we obtain

$$
\begin{gathered}
\frac{\partial K_{1}^{0}}{\partial \eta_{1}}=\frac{\partial K_{1}^{0}}{\partial \xi_{1}}=-\frac{u_{1}^{\prime \prime}}{u_{1}^{\prime \prime}+\beta R E\left[u_{2}^{\prime \prime} \cdot\left(R-\partial K_{2}^{0} / \partial K_{1}\right)\right]}<0 \\
\frac{\partial K_{1}^{0}}{\partial \eta_{2}}=\frac{\beta R E\left[u_{2}^{\prime \prime}\left(1+\partial K_{2}^{0} / \partial \eta_{2}\right)\right]}{u_{1}^{\prime \prime}+\beta R E\left[u_{2}^{\prime \prime} \cdot\left(R-\partial K_{2}^{0} / \partial K_{1}\right)\right]}>0 \\
\frac{\partial K_{1}^{0}}{\partial \eta_{3}}=\frac{\beta R E\left[u_{2}^{\prime \prime} \cdot \partial K_{2}^{0} / \partial \eta_{3}\right]}{u_{1}^{\prime \prime}+\beta R E\left[u_{2}^{\prime \prime} \cdot\left(R-\partial K_{2}^{0} / \partial K_{1}\right)\right]}
\end{gathered}
$$


where

$$
\partial^{2} V_{1} / \partial K_{2}^{2}=u_{2}^{\prime \prime}+\beta R \cdot E\left[u_{2}^{\prime \prime} \cdot\left(R-\partial K_{2}^{0} / \partial K_{1}\right)\right]<0
$$

at the optimum. The same reasoning holds here as in that relating to the decision in period 2. Increases in the fixed component of income in seasons 1 and 2 are transferred, in part, to augment the fixed components of income, and hence consumption, in the other two periods. Such an increase in season 3 will do likewise if the probability of default and its derivative are sufficiently small.

To close, it should be remarked that if, at the optimum, the agent does not borrow in a particular season, then an increase in $\eta_{t}$ will not change that decision if the associated derivative of $K_{t}^{0}$ is negative; but if it is positive, he will switch to borrowing in that season if the said increase is sufficiently large.

\section{The Extended Model: Production}

A key assumption of the basic model is that the processes that generate income, as represented by $\eta_{t}$ and $F_{t}\left(\xi_{t}\right)$, are wholly independent of the level of borrowing. This rules out, strictly speaking, borrowing for productive purposes, such as cultivation or keeping livestock If a household does pursue such productive activities and borrows to finance them, the model must be extended to accordingly.

Cultivation begins in season 2 and the crop is harvested in season 3. Let the total outlay on inputs that the household must buy in - certified seeds, fertilisers, pesticides, diesel and tractor services - be denoted by $x$. This outlay must be made at the very start of season 2. Eq.(2) now reads

$$
c_{2}(\tau)=\xi_{2}(\tau)+\eta_{2}(\tau)+K_{2}(\tau)-x(\tau)-R(\tau) K_{1}(\tau)
$$

The level of $x(\tau)$ will affect the distribution of the variate $\Xi_{3}(\tau)$. Let $G_{3}\left(\xi_{3}, x\right)$ denote the distribution function induced by the outlay $x$. 
Assumption 2. $G_{3}\left(\xi_{3}, x\right)$ first-order stochastically dominates $G_{3}\left(\xi_{3}, x^{\prime}\right)$ iff $x>x^{\prime}{ }^{4}$ Let $G_{3}$ be twice continuously differentiable in both arguments.

Remark. $\xi_{3}$ is the resulting gross income: Assumption 2 does not necessarily imply that $G_{3}\left(\xi_{3}-x, x\right)$ first-order stochastically dominates $G_{3}\left(\xi_{3}-x^{\prime}, x^{\prime}\right)$.

If no outlays on such inputs are made, it is assumed that production with 'traditional' techniques of cultivation is possible with the household's own endowments. This is precisely the setting of Section 2 once more, so that $G_{3}\left(\xi_{3}, 0\right)=F_{3}\left(\xi_{3}\right)$. For a household that does not borrow for production, whether by choice or because it has been shut out of the credit market, $F_{3}\left(\xi_{3}\right)$ represents its reservation (outside) option.

\subsection{Season 3}

The argument in Section 2.1 also holds here, $K_{2}$ having been chosen in season 2 .

\subsection{Season 2}

There are now two decision variables, $K_{2}$ and $x$. Rewrite (5) as

$$
\begin{aligned}
V_{2}\left(\xi_{2}\right) & =u\left(c_{2}\right)+\beta\left[\int_{\xi_{3}^{1}(x)}^{\xi_{3}^{d}} u\left(\xi_{3}+\eta_{3}\right) \frac{\partial G_{3}}{\partial \xi_{3}} d \xi_{3}+\int_{\xi_{3}^{d}}^{\xi_{3}^{2}(x)} u\left(\xi_{3}+\eta_{3}-R K_{2}\right) \frac{\partial G_{3}}{\partial \xi_{3}} d \xi_{3}\right] \\
& +\beta \delta \cdot\left[p V^{0}-(1-p) V^{a}\right] .
\end{aligned}
$$

The f.o.c. w.r.t. $K_{2}$ is analogous to $(6)$ :

$$
u^{\prime}\left(c_{2}\right)-\beta R \int_{\xi_{3}^{d}}^{\xi_{3}^{2}} u^{\prime}\left(\xi_{3}+\eta_{3}-R K_{2}\right) \frac{\partial G_{3}}{\partial \xi_{3}} d \xi_{3} \leq 0, K_{2} \geq 0
$$

\footnotetext{
${ }^{4}$ The common assumption involves the allocation of land between a risk-free crop and a risky one that has a higher expected yield. See, e.g., Gerhke (2014) and Raghunathan and Hari (2014).
} 
That w.r.t. $x$ involves an induced change in $G_{3}$ :

$$
\begin{aligned}
& -\quad u^{\prime}\left(c_{2}\right)+\beta\left[\int_{\xi_{3}^{1}(x)}^{\xi_{3}^{d}} u\left(\xi_{3}+\eta_{3}\right) \frac{\partial^{2} G_{3}}{\partial x \partial \xi_{3}} d \xi_{3}+\int_{\xi_{3}^{d}}^{\xi_{3}^{2}(x)} u\left(\xi_{3}+\eta_{3}-R K_{2}\right) \frac{\partial G_{3}}{\partial \xi_{3}} d \xi_{3}\right] \\
& +\quad \beta \cdot\left[u\left(\xi_{3}^{2}(x)+\eta_{3}-R K_{2}\right) \frac{\partial G_{3}\left(\xi_{3}^{2}(x), x\right)}{\partial \xi_{3}} \frac{\partial \xi_{3}^{2}(x)}{\partial x}-u\left(\xi_{3}^{1}(x)+\eta_{3}\right) \frac{\partial G_{3}\left(\xi_{3}^{1}(x), x\right)}{\partial \xi_{3}} \frac{\partial \xi_{3}^{1}(x)}{\partial x}\right] \\
& \leq 0, \quad x \geq 0 .
\end{aligned}
$$

Differentiating both f.o.c. totally holding $\eta_{3}$ constant yields, assuming a full interior optimum,

$$
u^{\prime \prime}\left(c_{2}\right)\left(d \eta_{2}-R d K_{1}\right)+\left(\frac{\partial^{2} V_{2}^{0}}{\partial K_{2}^{2}} d K_{2}+\frac{\partial^{2} V_{2}^{0}}{\partial x \partial K_{2}} d x\right)=0
$$

and

$$
-u^{\prime \prime}\left(c_{2}\right)\left(d \eta_{2}-R d K_{1}\right)+\left(\frac{\partial^{2} V_{2}^{0}}{\partial K_{2} \partial x} d K_{2}+\frac{\partial^{2} V_{2}^{0}}{\partial x^{2}} d x\right)=0
$$

Hence,

$$
\left(\frac{\partial^{2} V_{2}^{0}}{\partial K_{2}^{2}}+\frac{\partial^{2} V_{2}^{0}}{\partial K_{2} \partial x}\right) d K_{2}=-\left(\frac{\partial^{2} V_{2}^{0}}{\partial x^{2}}+\frac{\partial^{2} V_{2}^{0}}{\partial x \partial K_{2}}\right) d x
$$

where cross-derivatives are equal.

At the optimum, $\partial^{2} V_{2}^{0} / \partial K_{2}^{2}<0$ and $\partial^{2} V_{2}^{0} / \partial x^{2}<0$. By inspection, $K_{2}$ and $x$ will move in opposite directions if the cross-derivatives are also negative or, if positive, the own second derivatives are sufficiently close in size. In order to determine whether $K_{2}$ and $x$ will ever move in the same direction, it is therefore necessary to determine whether the cross-derivatives are positive.

We obtain, from (17),

$$
\begin{aligned}
\frac{\partial^{2} V_{2}^{0}}{\partial K_{2} \partial x} & =-u^{\prime \prime}\left(c_{2}\right) \\
& -\beta R\left(\int_{\xi_{3}^{d}}^{\xi_{3}^{2}(x)} u^{\prime}\left(\xi_{3}+\eta_{3}-R K_{2}\right) \frac{\partial^{2} G_{3}}{\partial x \partial \xi_{3}} d \xi_{3}+u^{\prime}\left(\xi_{3}^{2}(x)+\eta_{3}-R K_{2}\right) \frac{\partial G_{3}\left(\xi_{3}^{2}(x), x\right)}{\partial \xi_{3}} \frac{\partial \xi_{3}^{2}(x)}{\partial x}\right)
\end{aligned}
$$

Now $\partial G_{3}\left(\xi_{3}, x\right) / \partial \xi_{3}$ is the density function of $\xi_{3}$ for any given $x$. In virtue of Assumption 2 , an increase in $x$ will shift this function to the right in such a way that the probability that $\xi_{3}$ exceeds any given value will rise. Equivalently, higher values of $\xi_{3}$ 
will be realised with higher probability. Since $u$ is strictly concave, the value of the integral in (18) is therefore decreasing in $x$. That is to say, the integral in the parentheses on the RHS of (23) is negative. The second term in parentheses is positive, unless the density of $\xi_{3}$ at the upper end of the support of $G_{3}$ is zero. Even if the said density is positive, $u^{\prime}$ takes its minimum value on the support at $\xi_{3}^{2}(x)$, and the associated derivative $\partial \xi_{3}^{2}(x) / \partial x$ will be small if the investment technology is sufficiently strongly concave. It follows at once that $\partial G_{3}\left(\xi_{3}^{2}(x), x\right) / \partial \xi_{3}=0$ is a strongly sufficient condition for $\partial^{2} V_{2}^{0} / \partial K_{2} \partial x>0$.

Since the Hessian matrix is negative semi-definite at the optimum, it is now seen from (22) that $K_{2}^{0}$ and $x^{0}$ will move in the same direction if the own second derivatives differ sufficiently in size, and that this difference is decreasing in the size of the crossderivatives.

To complete the comparative statics analysis, it will be convenient to denote the second derivatives of $V_{2}$ w.r.t. the arguments $K_{2}$ and $x$ by $\alpha_{i j}(i, j=1,2)$, respectively. From (20) and (22), we obtain

$$
u^{\prime \prime}\left(c_{2}\right) \cdot\left(d \eta_{2}-R d K_{1}\right)+\frac{\left(-\alpha_{11} \alpha_{22}+\alpha_{12}^{2}\right) d x}{\alpha_{11}+\alpha_{12}}=0
$$

Hence,

$$
\frac{\partial x}{\partial \eta_{2}}=-\frac{1}{R} \cdot \frac{\partial x}{\partial K_{1}}=\frac{\left(\alpha_{11}+\alpha_{12}\right) u^{\prime \prime}\left(c_{2}\right)}{\alpha_{11} \alpha_{22}-\alpha_{12}^{2}}>0 \text { according as } \alpha_{11}+\alpha_{12}>0
$$

and

$$
\frac{\partial K_{2}}{\partial \eta_{2}}=-\frac{1}{R} \cdot \frac{\partial x}{\partial K_{1}}=\frac{-\left(\alpha_{22}+\alpha_{12}\right) u^{\prime \prime}\left(c_{2}\right)}{\alpha_{11} \alpha_{22}-\alpha_{12}^{2}} \gtrless 0 \text { according as } \alpha_{22}+\alpha_{12} \gtrless 0 \text {. }
$$

In particular, $K_{2}^{0}$ and $x^{0}$ are both increasing (decreasing) in $\eta_{2}\left(K_{1}\right)$ if, and only if, $\alpha_{11}+\alpha_{12}<0$ and $\alpha_{22}+\alpha_{12}>0$.

Taking these twin conditions in turn, the former requires that $u$ be strongly concave in the neighbourhood of the optimum so as to outweigh the cross effect of any induced change in the marginal pay-off of $x$, that is to say, that there be a locally strong 
taste for a smooth path of consumption (equivalently, strong risk aversion). The latter condition requires, in contrast, that the rate at which the density function shifts in response to $x$ not fall so rapidly as to outweigh the cross effect of any induced change in the marginal pay-off of $K_{2}$, that is to say, that the investment technology be not too strongly concave. These conditions accord with intuition. For if a bit more debt is taken on in season 2 in the presence of a strong preference for a smooth path of consumption, then there must be the prospect of very favourable marginal returns on $x$ in season 3 when the debt falls due.

It is quite possible that one of the said conditions is violated, in which event, $x$ and $K_{2}$ may both contract in response to an increase in $\eta_{2}$, or move in opposite directions, in accordance with the possible patterns of inequalities in (24) and (25).

\subsection{Season 1}

The argument proceeds as in Section 2.1, whereby the optimality of both $K_{2}$ and $x$ is used in deriving the f.o.c., whose form (12) remains unaltered. Differentiating totally and rearranging terms, we obtain, for an interior solution,

$u^{\prime \prime}\left(c_{1}\right) \cdot d \eta_{1}+\left\{u^{\prime \prime}\left(c_{1}\right)+\beta R \cdot E\left[u^{\prime \prime}\left(c_{2}\right) \cdot\left(\left(R-\partial K_{2}^{0} / \partial K_{1}\right)+\left(1-\partial x^{0} / \partial K_{1}\right)\right)\right]\right\} \cdot d K_{1}=0$

or

$$
\frac{d K_{1}^{0}}{d \eta_{1}}=\frac{-u^{\prime \prime}\left(c_{1}\right)}{u^{\prime \prime}\left(c_{1}\right)+\beta R \cdot E\left[u^{\prime \prime}\left(c_{2}\right) \cdot\left(\left(R-\partial K_{2}^{0} / \partial K_{1}\right)+\left(1-\partial x^{0} / \partial K_{1}\right)\right)\right]}<0
$$

since the denominator must be negative at the optimum. Although the production decision in the following season is fully taken into account, only the motive to smooth consumption is directly at work.

Yet any changes in $K_{1}^{0}$ induced by changes in $\eta_{1}$ have consequences for decisions in season 2 that require some comment. Recalling (24) and (25), it is seen that an increase in $\eta_{1}$ will, by reducing $K_{1}^{0}$, increase both $K_{2}^{0}$ and $x^{0}$ when these move together and 
are decreasing in $K_{1}$, as just discussed at the close of Section 3.2. Under the requisite conditions in question, bigger transfers received in season 1 will promote both greater borrowing and investment in working capital in season 2, even though income itself cannot, by assumption, be transferred directly across seasons. Increases in $\eta_{1}$ and $\eta_{2}$ then pull in the same direction where decisions in season 2 are concerned.

\subsection{The model's implications for empirical analysis}

The model laid out above gives rise to a large number of potentially testable hypotheses. Our aim is to test some of them in the particular context of NREGS. Since this is an important policy intervention in the setting of a large developing country, its impact on borrowing is an important question in itself. Hence, we begin by laying out what the model would imply if one were interested in the impact of NREGS on households' annual borrowing. The programme's effect on this aggregate is important. Yet many of the standard large data sets for developing countries (for example, those of India's National Sample Survey) collect data on total current indebtedness, not borrowings in some reference period. Hence, it not possible to use such data to test what interests us here. When information is collected on borrowing, the typical reference period is the last 365 days, but with almost no indication of the season in which it occurred. Similarly, information on transfers is also simply annual in nature. We formulate the hypotheses which would be relevant for applications using such data.

With an eye on the structure of the model's two variants, and anticipating the empirical analysis in the sections that follow, we classify loans to finance food and consequences of illnesses and deaths as consumption loans and those to finance cultivation as production loans. For households that do not cultivate, $K_{t}$ can be interpreted as a consumption loan taken in season $t$. Such a household's annual borrowings are simply $K \equiv K_{1}+K_{2}$. How NREGS transfers would affect $K$, according to the results in

Section 2, depends not only on their size in aggregate, but also on their seasonal distri- 
bution $\left(\eta_{1}, \eta_{2}, \eta_{3}\right)$. While $K_{t}$ is decreasing in the size of the contemporaneous transfer $\eta_{t}$, transfers in other seasons have mixed effects. $K_{1}$ is increasing in $\eta_{2}$. Observe that $\eta_{1}$ has no direct effect on $K_{2}$; but since $K_{2}$ moves in the same direction as $K_{1}$ (recall (9)), a hefty increase in $\eta_{1}$ can, by reducing $K_{1}$, outweigh the effect of a modest increase in $\eta_{2}$ on $K_{2}$ and so cause it to fall. The effect of an increase in $\eta_{3}$ on $K_{1}$ and $K_{2}$, respectively, is ambiguous. The relation between annual borrowing for consumption and annual transfers received is therefore ambiguous: the timing of needs and transfers matters.

The effect of transfers on production loans is subject, in principle, to similar ambiguity, with the additional complication that borrowing in season 2 is connected with financing both consumption and working capital. In the discussion following eqs.(25) and (26), however, it is argued that, under certain plausible restrictions on preferences and the agricultural technology, both borrowing and outlays on working capital in season 2 are increasing in $\eta_{1}$ and $\eta_{2}$. If, as in the region studied, there is effectively one cultivation season, the timing of loans for production is correspondingly fixed, and the distinction between seasonal and annual borrowing for that purpose is not vital.

A salient feature of our data is that they contain some important details on the timing of borrowings and transfers. While the exact month of NGREGS payments to individual households is not known, a monthly plot of NREGS payments for the village as a whole for the years 2012 and 2013 gives us a good idea of when NREGS payments are made: largely in season 1 , followed at some distance by season 3 . Hence, we shall test some of the models' implications concerning the seasonal pattern of borrowing. As noted above, $K_{1}$ is decreasing in $\eta_{1}$, while transfers later in the year can raise $K_{1}$. As for cultivating households, the fact that transfers in season 1 are overwhelmingly larger than those in season 2 implies that $K_{2}$ may well be increasing in annual transfers, despite the ambiguity surrounding the effects of changes in $\eta_{3}$. 


\section{Data and Summary Statistics}

This study is based on information collected from 279 households spread over 30 villages in Odisha, an eastern state of India, for the calendar year 2013. Six villages were drawn from each of five administrative blocks: Titlagarh, Saintala, Muribahal and Bongomunda in Bolangir district, and Kesinga in Kalahandi district. The households stem from an original sample of 240 households first surveyed in $2001-02 .{ }^{5}$ This remote rural area is particularly fitted for our study, since it is poor and notoriously prone to drought. This is a region where a policy like NREGS should have some bite. Indeed, both districts were chosen for roll-out in the first phase in $2006 .^{6}$

The survey instrument recorded, among other things, information on households' demographic and wealth characteristics, employment activities, loans taken and morbidity shocks over the year. ${ }^{7}$ Data were sought separately for the period January to June (the Rabi season) and July to December (the Kharif season). Respondents were asked to indicate the purpose of loans and the month when they were taken. This is especially useful for the empirical analysis of the models laid out in Sections 2 and 3. Data on village characteristics were also collected, together with a survey of the Gram Panchayat (a collection of villages forming the lowest level of public administration). In particular, details were obtained concerning the Sarpanch (headman), who is elected

\footnotetext{
${ }^{5}$ The current survey is part of a larger project that has collected longitudinal data on the said 240 households and some of their subsequent splits. See van Dillen (2008) for an account of the survey's design and original purpose, as well as a description of the region.

${ }^{6}$ NREGS was rolled out in three phases, in the first, to the most backward districts of India (Zimmerman, 2012). We do not use logitudinal data. The previous survey, in 2009, did not include questions on borrowing. The surveys in 2004 and earlier are too far back in time to make household fixed effects estimation useful. Even if we were to use data from 2004, the usual identification method of using a pre-post, difference-in-difference estimator using the staggered phasing of NREGS across districts would be a non-starter, since both districts got NREGS in the first phase.

${ }^{7}$ The survey was conducted in two waves. Data were collected in October and November, 2013. The surveyors returned in February in 2014 to get information for the months in 2013 that followed their first visit and to resolve any questions that had arisen in the first stage of cleaning the data.
} 
democratically and is responsible, together with the local beauracracy, for the working of public schemes in villages that come under his or her jurisdiction. ${ }^{8}$ The summary statistics are set out in Table 1.

About one half of the sample households borrowed in 2013. Forty-three percent did so to defray expenditures on medical treatment, to purchase agricultural inputs, to finance current consumption, and to pay for funeral expenses. ${ }^{9}$ Figure 1 shows the monthly timing of loans destined for various purposes, as reported by the households. While credit can be fungible, a look at the figure on the timing of various kinds of loans reveals that some loans are clearly taken for a particular need at a certain time of the year. For example, while health loans are taken largely in the months from May to November, loans for agricultural inputs are taken primarily in the months of June and July, as the monsoon sets in. Thus, in the spirit of the model, we define the categories consumption loans and production loans. Consumption loans are loans taken to defray expenditures on medical treatment, food and funerals. Production loans are taken to buy agricultural inputs. To be consistent with the model, we analyse only these categories of loans taken from March 2013 to the end of that calendar year; and we refer to a household as having taken a loan only if the loan in question falls into one of these two categories.

Twenty-seven percent of all households took consumption loans, 22 percent production loans, and about one in eight of all these combined took both types. The total borrowings for these two purposes accounted for around $80 \%$ of the total amount borrowed for all purposes. The average sizes of consumption and production loans were Rs. 8240 and Rs.13, 221, respectively. ${ }^{10}$

\footnotetext{
${ }^{8}$ Wherever possible, the survey collected administrative records.

${ }^{9}$ We maintain the spirit of the model, wherein consumption loans are taken as a response to shocks. Since loans to purchase assets, build houses, and celebrate weddings and festivals are more planned, we exclude them from our definitions of consumption and production loans. If they are included, 50.2 percent of sampled households took loans in 2013.

${ }^{10}$ In PPP, these correspond to 458 and 735 US\$, respectively. The average annual household con-
} 
The sources of credit are diverse, formal and informal alike. The village-level survey yields information not only on the different types of lenders, but also on whether they lend for certain purposes and whether borrowers can - or must - provide collateral. Moneylenders figure as the leading source of consumption credit (focus groups in 27 villages listed them as the most common source). There are, however, two secondrank types, namely, banks for households with some collateral and self-help groups (SHGs) for those with none. The sources of production loans are somewhat different. Respondent groups in 17 villages claimed that cooperative societies constitute the most important source for households with some collateral, followed by banks. For those with no collateral, moneylenders were ranked first in 27 villages, followed by SHGs. The responses in the household survey tell a similar story, with moneylenders accounting for 50.1 percent of consumption loans. Loans from banks and SHGs each constitute 6 percent, and friends and relatives for the rest. As for production loans, 48 percent came from banks and coops and 43 percent from moneylenders.

A preliminary analysis of the impact of participating in NREGS on households' borrowings, based on the summary statistics, yields findings consistent with the model. In season 1, when there are only consumption loans, NREGS income should reduce consumption credit; but in season 2 , borrowing for both consumption and production should increase. Hence, the overall impact of NREGS income on total consumption loans and total borrowing (taken over seasons 1 and 2) depends on the relative magnitude of the two effects, and the model predicts an ambiguous outcome. In fact, the proportion of households that took loans and the average amount of credit taken do not vary, statistically, with participation in NREGS, nor does the share of households with consumption loans; but the amount of credit taken for consumption needs does so (see Table 2). Households that participated in NREGS borrowed Rs. 1738 less for consumption purposes than those that did not, a difference that is statistically significant sumption expenditure for southern Odisha in 2012 was 2352 US\$ (for a household size of 4). Authors' calculation from the NSS 68th Round, 2011-12. 
at the 5 percent level. While borrowing for production is unaffected by participation in NREGS, statistically speaking, the point estimates of the share of households with production loans and the average size of production loan are both higher for participating households.

Such bivariate analyses suffer from problems of confoundedness. Although all households have a right to work 100 days under NREGS, it is very likely that there is self-selection into the scheme. As Table 2 shows, households that participated are statistically different from those that did not. The former are less likely to be tribal; they have more household members, a larger proportion of adult males and younger members on average; and they are also more likely to possess BPL or AAY cards. ${ }^{11}$ Given these systematic differences in characteristics, it is important to conduct a multivariate regression analysis.

\section{The Empirical Model}

To test the hypotheses suggested by the theoretical model, it is necessary, first, to control for observable differences between households that participate in NREGS and those that do not, and second, to address the fact that households need to work on NREGS projects in order to get an income transfer. While the model is silent about the choice of labour supply to NREGS, the empirical analysis must deal with the potential endogeneity of the participation decision. For it is clear that a household's unobserved characteristics can affect both its borrowing behavior and participation in NREGS.

To begin with, we model the probability of taking a loan. Let the discrete variable

\footnotetext{
${ }^{11}$ The state government uses the classification poor and very poor households. The latter can buy grains at a highly subsidized rate from the public distribution system (PDS) under the Antyodyaya Anna Yojana (for which they are given AAY cards). The former can also buy grains from the PDS; the rate is slightly higher, though well below the market price. These households are given BPL (Below Poverty Line) cards.
} 
$L_{i v b}^{j} \in\{0,1\}$ take the value 1 if a loan of type $j$ is taken by household $i$ living in village $v$ belonging to block $b$, and 0 otherwise. Here, $j \in(A, C, P)$, where $A$ stands for a loan of either kind (recall that the analysis is restricted to consumption and production loans), $C$ denotes a consumption loan and $P$ a production loan. Whether a household takes a loan of a particular type may depend on its characteristics, the vector of which is denoted by $\mathbf{H}_{i v b}$.

The main characteristic we are interested in is the discrete (participation) variable NREGS $S_{i v b} \in\{0,1\}$. However, other characteristics - social, economic and demographic - may also affect both $L_{i v b}^{j}$ and NREGS $S_{i v b}$. The social groups known as Scheduled Castes $(S C)$, Scheduled Tribes $(S T)$ and Other Backward Castes $(O B C)$ comprise virtually the whole of the sample and are also legal categories. With the first as reference group, we include $(S T)$ and $(O B C)$ as dummy variables. We also include the amount of land owned and a dummy variable for whether the household has a BPL/AAY card as indicators of its economic well-being. ${ }^{12}$ We capture demographic differences by taking into account the household's size, the proportion of its members who are male and above 15 years in age, its members' mean age and the years of education of its most educated member. ${ }^{13}$

The chief shocks that assail these households are bouts of acute illness among its members (van Dillen, 2008), and the survey yields a measure of them, namely, the total number, as reported by respondents. Deaths, whatever the cause and whatever the extent of treatment, were also recorded. Since we are concerned with shocks, we exclude all episodes of morbidity due to chronic diseases like epilepsy, paralysis

\footnotetext{
${ }^{12}$ We could have added asset quartiles based on a principal component analysis of the ownership of consumer durables and livestock. However, loans were taken during this period to buy these assets. Hence, including of asset quartiles would be invalid - though our results are robust to their inclusion.

${ }^{13}$ About 95 percent of households are male-headed. It is not clear whether the reported household head indeed makes the relevant decisions, since respondents often report the oldest member to be the household head. Given our relatively small sample size, we omit this variable to come up with a parsimonious specification. The results are, however, robust to its inclusion.
} 
and pregnancy/child birth (which is often reported as a medical condition). Given this exclusion, most of the episodes were due to malaria, viral fever and diarrhoea. Together, these ailments account for 68 percent of the 153 episodes reported in the rabi season and 62 percent of the 342 episodes in the kharif season. ${ }^{14}$ Households are surely aware that morbidity is higher in the monsoon months, though falling ill is not certain. Indeed, 18 percent of the households suffered not a single episode of morbidity. Nor does this happy outcome necessarily reflect the household's economic status: 67 percent of those that suffered no episodes were BPL households. ${ }^{15}$ To account for the need to meet funeral expenses, we include a dummy variable which indicates whether the household has experienced a death of a member.

We control for local village effects by including a variety of village characteristics, denoted by the vector $\mathbf{X}_{v b}$. We include the total area of the village, the proportion of village land irrigated and the total number of households registered for NREGS. ${ }^{16}$ (We do not include population, as the correlation between the number of households so registered and the village population is 0.6.) Quartiles representing a village's level of development are based on quartiles of the first factor from a principal component analysis of the distance to amenities. ${ }^{17}$ Finally, there are the distances to administrative centres, namely, district headquarters, block headquarters and the panchayat office.

The theoretical model is largely silent on the structure of competition among lenders. The borrower is assumed to be able to choose the size of the loan at a given rate of interest, whereby the latter may vary across seasons, households and lenders. Since the

\footnotetext{
${ }^{14}$ The other ailments include unknown fevers, coughs and colds, jaundice, typhoid, eye allergies and skin allergies.

${ }^{15}$ We do not use the total number of days of morbidity, since that may be affected by borrowing to finance treatment. The results still go through if a discrete $\{0,1\}$ variable is used instead of the count variable.

${ }^{16}$ These are taken from http://nrega.nic.in/netnrega/home.aspx.

${ }^{17}$ Bus station, chemist, train station, primary health centre, bank, cooperative society, public hospital, primary school, secondary school, high school, local vegetable market, cattle market, police station, and telephone booth.
} 
size of the penalty in the event of default depends on the household's characteristics, the cost of funds is free to vary in various dimensions. Where formal credit is concerned, we represent these considerations by the distance from the centre of the village to the nearest commercial bank and cooperative society, respectively. The existence or otherwise of a village SHG is denoted by a dummy variable. As for local informal lenders' market power, we employ a measure of concentration in landownership as a proxy (Hatlebakk, 2009): $M_{v b}$ takes the value 0 if the number of households owning more than 5 acres is zero or greater than three, and 1 otherwise. The vector of variables representing the supply-side structure is denoted by $\mathbf{S}_{v b}$.

The inclusion of village-level variables can, in principle, be avoided by the inclusion of village fixed effects. With a sample of 30 villages, however, this will lead to an efficiency problem, for the sample comprises only 279 observations. Hence, we estimate the following linear probability model (LPM) with block fixed effects $\left(\alpha_{b}\right):{ }^{18}$

$$
L_{i v b}^{j}=\alpha_{b}+\theta \cdot N R E G S_{i v b}+\beta \cdot \mathbf{H}_{i v b}+\delta \cdot \mathbf{X}_{v b}+\rho \cdot \mathbf{S}_{v b}+\varepsilon_{i v b} .
$$

We cluster standard errors at the village level and report Huber-White robust standard errors. The parameter of interest is $\theta$.

To exploit the results in Sections 2 and 3 more fully, we also estimate a specification in which the regressand is $K_{i v b}^{j}$, the amount of credit taken. Since more than half the sample did not take credit, a tobit model (with instrumental variable) is employed.

Our empirical models control for systematic observable differences between households. However, we are still beset by the problem that participating in NREGS and borrowing are decisions influenced by the same unobservables. Hence, the $O L S$ estimates are inconsistent. We therefore turn to identification.

\footnotetext{
${ }^{18} \mathrm{~A}$ probit model yields similar results.
} 


\subsection{Identification}

We approach the problem of endogeneity using an Instrumental Variables (IV) estimator, instrumenting participation in NREGS by a dummy variable that indicates if the position of sarpanch for the household's village is under female reservation. The argument in favour of this choice runs as follows.

In 1993, an amendment to the constitution of India required states of India to devolve more power over expenditures to local village councils (Gram Panchayats, henceforth GPs) and to reserve one-third of all positions of chief (Sarpanch/Pradhan) to women. In all subsequent elections, GPs have been randomly selected for reservation, provided they were not reserved in the previous election. Many studies of the impact of female sarpanches have exploited this randomization. Chattopadhyay and Duflo (2004) show that the reservation in West Bengal and Rajasthan improved the provision of education (fewer informal schools), drinking water facilities and sanitation. The effect on irrigation and metalled roads was ambiguous. In contrast, Rajaraman and Gupta (2012) use data from four states of India to establish that once the incidence of water-borne diseases like cholera and diarrhoea are controlled for, the reservation had no differential impact on expenditures on water and sanitation. As for the personal attributes of the female sarpanches, Ban and Rao (2008), in their study of four South Indian states, find that they are significantly less educated, less knowledgeable, less politically experienced and younger than unreserved presidents. However, they conclude that the female sarpanches, as actors, were not 'mere tokens'. Bardhan et al. (2010) find that female reservations in West Bengal are associated with a significant worsening of within-village targeting measures to aid socio-economically disadvantaged households, and no improvement on any other targeting dimension.

Of direct relevance to our study is Afridi et al.'s (2014) investigation of the impact of female reservation on the functioning of NREGS in the neighbouring state of Andhra Pradesh. They find larger program inefficiencies and leakages in reserved GPs, and 
posit that political and administrative inexperience make such councils more vulnerable to bureaucratic capture. In particular, labor- and materials-related misappropriations are likely to be higher in such GPs, but especially so in the early years of tenure. Wage payments, too, are more delayed in the initial years. BPL households have a lower probability of getting NREGS work. ${ }^{19}$

GP elections were held in February 2012, so that female sarpaches were relatively inexperienced during the rabi season of 2013, when the bulk of NREGS work was carried out. For female reservation status to be a credible instrument, two conditions need to be satisfied. First, it should be correlated with the endogenous variable $N R E G S_{i v b}$. Second, it should meet the exclusion criterion, that is, it must not affect credit through any other omitted channel. While conclusive evidence on the first condition will be provided when we discuss the first stage of the IV results in Section 6, we provide some suggestive, but not conclusive, evidence that the reservation may be bad for NREGS outcomes at the village level.

Tables $A .1$ and $A .2$ report the results of regressing two measures of NREGS-outcomes on the female reservation and some other salient village covariates. The measures are the total number of households in the village that received NREGS work in 2013 and the associated total number of persons-days of NREGS work carried out. In column (1) of each panel, the only regressor is the female reservation, which was in force in nine of the 30 villages. Since the outcomes may vary with the demand for NREGS work, we then add three additional variables. First, there is the number of households in the village registered for such work. (The registration of households started in 2006, with very little annual variation after 2010.) Second, there is the village's development index. Here, we use only the value of the first factor from the principal component analysis to keep the number of variables to a minimum. Third, there is the district-level rainfall shock, measured as the deviation from the long-run average, as reported in the

\footnotetext{
${ }^{19}$ It should be added that, after gaining experience, female sarpanches did no worse than their male counterparts, at least where NREGS is concerned.
} 
Indian Meteorological Database. It is seen from both columns 2 that after controlling for demand factors, the impact of female reservation is negative and significant.

Two other kinds of political reservations are also randomly assigned, one for each of the disadvantaged groups scheduled castes and scheduled tribes. All three reservations can apply at the same time: a GP can be reserved for a female scheduled caste candidate. This could confound some of the effect of female reservation. Column (3) therefore reports the results when a dummy variable for each caste group reservation status is included, and that for female reservation is omitted. All the variables are included in column (4). The adverse impact of female reservation remains; but the coefficients of the dummy variables for caste reservation status are small in absolute magnitude, their signs are not robust and none is significant. Henceforth, we ignore them.

Our results on the correlation between NREGS outcomes at the village level and female reservation status suggest that this partial correlation is more precisely estimated when we control for village characteristics. This raises the question of whether such characteristics vary with female reservation status. While randomization of the latter ensures that the selection of females to the position of sarpanch is not driven by village characteristics, it is possible that in a small sample such as ours, the reservation status is correlated with the covariates. The summary statistics are set out in Table A3.

Taking household characteristics (except borrowing and NREGS participation) first, only the proportion of male adults and the education variable are significantly different, with households in non-reserved villages having, on average, higher values. However, this correlation could be driven by differences in village-level prosperity. To check for this, we regress female reservation on the list of household covariates as well as the village-level covariates discussed above. Once we condition for the latter, all household variables are insignificant, with the exception of household size, which is significant at the 10 percent level and has a negative sign. A joint $F$-test of all the household 
covariates yields a value of $0.77(p=0.65)$. Thus, in terms of household characteristics, the sample is fairly well balanced.

The story is different when we come to the characteristics of the villages in which the sample households resided. The proportion of households living in villages that fall into the two lower quartiles of the development index was higher, on average, when those villages were also under the reservation. Less exactly expressed, villages under the reservation are poorer, which is consistent with a higher average number of registered households. These villages are also more remote: on average, their households are almost $15 \mathrm{~km}$. farther away from district headquarters, $1.5 \mathrm{~km}$. from block headquarters, $0.7 \mathrm{~km}$. from panchayat headquarters, almost $1 \mathrm{~km}$. from banks and $1.6 \mathrm{~km}$. from cooperative societies. They face less competitive informal credit markets, but they are more likely to have SHGs. Their villages are also larger in area. It is therefore important to include these village-level covariates as independent variables.

There is evidence that the sarpanch's education level often correlates well with public expenditure on, and targeting of, BPL (Besley et al., 2012; McManus, 2014). Female sarpanches typically are poorly educated, and in the survey villages, those in femalereserved positions have, on average, almost 5 fewer years of education than their counterparts in unreserved ones. This drawback may have a direct impact on the working of the public distribution system and hence the need for credit to buy food. By including the sarpanch's education as a control, what we pick up as the impact of female reservation on NREGS implementation is the incumbents' relative inexperience in the early stages of their tenure, when having to deal with the administration of a complicated scheme like NREGS, with its heavy reporting requirements. Managing certain other forms of expenditures is less taxing, a point to which we return in Section 6.2. 


\section{Main Results}

It will be useful to begin by recalling certain results from Sections 2 and 3. When the motive to borrow is purely to smooth consumption, an increase in the certain component of income in season 1 will induce less borrowing in that season. When production also enters the picture, such an increase will induce both more borrowing and more investment in working capital in season 2 if the taste for a smooth path of consumption is fairly strong and the productive technology is not too strongly concave. Indeed, most NREGS payments are received in season 1 and the lion's share of borrowing for production occurs at the close of season 1 and the start of season 2 (Figures 1 and 2). The fact that only 12 percent of households that borrowed did so for both purposes is happily in keeping with the separate regressions that follow. ${ }^{20}$

As noted above, OLS estimates are inconsistent, but they serve as a benchmark. Columns (1)-(3) of Table 3 report the results for $L^{A}, L^{C}$ and $L^{P}$, respectively. The coefficient of a household's NREGS participation, the regressor of chief interest, is negative and insignificant in all three. That of the years of education of the household's most educated member, which is usually quite strongly correlated with income, is also negative, and significant at the 10 percent level in $L^{A}$ and $L^{C}$. Sickness and death in the family have positive coefficients. Those for $L^{A}$ and $L^{C}$ are significant at the 5 percent level or better; in $L^{P}$, only that of morbidity is significant, and then at the 10 percent level. Otherwise, only quartile 2 of the village development index and distance to the block $\mathrm{HQ}$ in $L^{C}$ are significant at conventional levels. Their coefficients are positive and negative, respectively.

We turn to the $I V$ estimation procedure, beginning with the first stage. The coefficient of the dummy variable representing the female reservation is always negative and

\footnotetext{
${ }^{20}$ We do not consider sub-samples of cultivator and non-cultivator households, since cultivation is an endogenous decision. A stratification of the sample into landless and landed households leaves us with too few observations in each stratum.
} 
significant at the 1 percent level. Households living in these villages are 39 percentage points less likely to participate in NREGS. The Kleibergen-Paap Wald rk F-statistic is 14.65 , which lies above the 15 percent critical value for the Stock-Yogo weak identification test. ${ }^{21}$ Hence, our instrument is not weak. The other results (available on request) indicate that NREGS participation is increasing in the proportion of males in the household and the registered number of NREGS households in the village. Households in villages farther away from the district and panchayat HQ are also more likely to participate in NREGS. ${ }^{22}$

With these strong first-stage results in hand, we move to the second stage. Participation in NREGS has effects on $L^{C}$ and $L^{P}$ in accordance with the theoretical model's predictions (see columns 5 and 6). The probability of taking a consumption loan falls by 0.25 , that of taking a production loan increases by 0.6 , and both estimates are significant at the 10 percent level. If both kinds of loans are pooled (column 4), the coefficient is positive, but very imprecisely estimated, which is consistent with the resulting ambiguity in the model's prediction.

The impact of other covariates is largely in line with the OLS estimates, but the $I V$ ones are generally more precise. The presence of an SHG in the village raises the probability of taking a consumption loan by 12 percentage points, and households whose members are older on average are less likely to do so. An increase in the number of registered households in a village reduces the probability that any particular household borrows for production. It is difficult to interpret the impact of village-level variables in reduced-form regressions. The Sarpanch's education and the village's remoteness

\footnotetext{
${ }^{21}$ The Kleibegen-Paap Wald statistic and not the Craig-Donald statistic is the relevant test statistic for a model with robust and clustered standard errors.

${ }^{22}$ The village development indices are themselves insignificant. It may be argued that inclusion of many potentially correlated variables is the cause. We decided to include them nevertheless, as exclusion of subsets of these variables reduces the Kleibergen-Paap F statistic, sometimes by 50 percent, rendering the instrument weaker. However, as long as we include village-level controls, our main results remain unchanged.
} 
correlate with its level of development, which may affect both demand and supply. The reduced-form coefficients measure the net impact.

With the theoretical results still in view, we now analyse the impact of NREGS on borrowing at the intensive margin, that is, on the amount of borrowed. Since the majority of households do not borrow for either purpose, we employ a tobit model with instrumentation. It is desirable in such models to use a continuous endogenous regressor, so we substitute the total number of days worked under NREGS for the participation variable. At the first stage, as in the LPM, the female reservation status is negative and highly significant (see Table 4). At the second stage, we examine only consumption and production loans separately, since pooling them is unlikely to yield any clear insights. One more day of NREGS work reduces the amount of a consumption loan, allowing for censoring at zero, by Rs. 72 (the slope coefficient is -Rs. 273). Given that the NREGS daily wage in 2013 was Rs. 147, this estimate is very plausible, especially if one takes into account the anecdotal evidence that households often need to pay a bribe to get NREGS work (Afridi et al., 2014). The corresponding marginal effect of one more day of NREGS work on the amount of a production loan is Rs. 277. This is qualitatively consistent with the theoretical prediction, and it indicates that NREGS payments induce cultivating households to take riskier positions. ${ }^{23}$

\subsection{Seasonal Analysis}

In order to impose greater consistency with the model's time-structure, we define all observed borrowing in season 1 to be for consumption. Borrowing in season 2 comprises consumption loans taken in the months of July through October and all production loans. ${ }^{24}$ Since we have data for only the calendar year 2013, the data for season 3 are incomplete, and hence we ignore that season. While it is possible to assign borrowing

\footnotetext{
${ }^{23}$ Raghunathan and Fields (2015) employ a different model to show that households are more likely to borrow for riskier projects when they work on NREGS.

${ }^{24}$ These are largely taken in the months of June and July, and so straddle seasons 1 and 2.
} 
to seasons, it is not possible to do so with NREGS work. Respondents usually recall imperfectly exactly when the household's members worked. What matters for the model, moreover, is not when they worked, but when they got paid. It is possible, however, to figure out when households are more likely to get paid by looking at the official records of the monthly distribution of total NREGS payments in the village, which are depicted for 2012 and 2013 in Figure 2. ${ }^{25}$ Payments are rather concentrated early in the year and then in the months of May and June. This pattern is consistent with the need for work in the lean season. Hence most of the payments for NREGS are made in season 1.

According to the LPM estimates (see Table 5), participating households are 19 percentage points less likely to borrow in season 1, and 61 percentage points more likely to borrow in season 2 , though the latter estimate is not precise $(p=0.15)$. The tobit model yields an estimated marginal effect, allowing for censoring, of one more day of NREGS work in season 1 of - Rs. 373. This rather startlingly high effect is driven by two outliers. If they are omitted, the estimated marginal effect is -130 , still somewhat higher than that in Table $4 .^{26}$ The corresponding marginal impact on total borrowing in season 2 is 138, which is significant at the 10 percent level and accords with the model's qualitative prediction.

\footnotetext{
${ }^{25}$ Household-level records on the timing of NREGS work often fail to match official records. In many cases, households report that they have worked and been paid without any record of their doing so in official records. Given the poor state of book-keeping, we do not use the monthly distribution of NREGS work reported by the household. Instead, we use the village-level seasonality of payments, since this needs to be reported accurately for the auditing of funds by the central government.

${ }^{26}$ An analysis of loan types $A, C$ and $P$ does not show outliers when we aggregate over the three seasons. Hence, we use the full sample in the main section above. Those results are qualitatively robust to dropping the two observations.
} 


\subsection{Robustness}

Other covariates may confound our analysis, but may themselves be endogenous. The aim here is to check whether the impact of NREGS participation is robust to their inclusion. We use the LPM for this purpose; similar results are obtained using the tobit model. We compare the coefficient of NREGS participation in the baseline regression (columns 1 and 5 of Table 6 ) with its value in the alternative specifications listed below (columns 2-4 and 6-8).

\section{Risk-bearing: outstanding debt}

Decisions to borrow depend critically on agents' risk aversion. While we do not have such a measure for our households, we posit that previous loan behaviour may be a proxy for the willingness to bear risk. Hence, we control for the value of principal and accumulated interest outstanding at end of February 2013. The regression coefficient remains unchanged.

\section{Other public policies}

The sample villages belong to the so-called $K B K$ area of Odisha, whose poverty has long since made it the object of the government's attention. It is unlikely that any special aggregate measures will have a significant effect on our results, since we use intra-block variation in our empirical analysis; but there may be village-level differences in the outcomes of these interventions that correlate with female reservation status. Hence, we check if our results are robust to the inclusion of other policy outcomes at that level.

There is evidence that the provision of all-weather rural roads under PMGSY lowers morbidity (Bell and Van Dillen, 2015). We have already controlled for the number of episodes of morbidity suffered by households. In addition, we control for the distance from the village to the all-weather road network.

A more general measure is the total expenditure on all other schemes during the 
financial year 2013-2014. The main sources are Finance Commission funds (both the 13th Finance Commission and Odisha's state finance commission) and Gram Panchayat funds. Also included are expenditures incurred under the Harishchandra scheme, which gives loans for funerals, the Indira Awas Yojana, which provides loans for building a house, the Kendu-leaf scheme and various pension and support schemes for the old, widows and disabled. The introduction of neither PMGSY nor the general level of public expenditures produces a significant change in the coefficient of interest. ${ }^{27}$

\section{Conclusion}

How to smooth consumption is a problem that confronts all households living in risky environments. Credit markets typically function poorly in these settings, which prompts public intervention. An income guarantee is a natural candidate. India's National Rural Employment Guarantee Scheme is, in spirit, such a guarantee. For households may supply labor to work on public projects that run during the lean season, when there is otherwise little work to be done and many households would willingly take up additional employment, even at low wages, if offers were forthcoming.

In this paper, we have analysed the impact of income guarantees on borrowing by households. To do so, we develop a three-season theoretical model and test some of its results empirically using a sample of 279 households in a semi-arid region of Odisha. Two central theoretical results are confirmed. First, working in NREGS lowers borrowing for consumption: an additional day of work at the regulated wage reduces the estimated amount borrowed for that purpose by about half the wage. If the work is done in the lean season, the estimated effect on such borrowing in that season is stronger still: it is roughly one-to-one. Second, working in NREGS after the lean season increases borrowing for production purposes. An additional day of work

\footnotetext{
${ }^{27}$ We do not test the impact of drinking water and sanitation, as we already control for morbidity. Besides, 93 percent of the hamlets surveyed have at least a public tubewell.
} 
increases such borrowing by an estimated amount that is almost twice as large.

The model and the empirical results obtained inform the general debate on the impact of providing income guarantees in risky environments in two ways. First, ascertaining the impact of income guarantees needs a nuanced treatment of borrowing. Large cross-section surveys typically carry out a debt assessment with a reference period of a year. Our analysis, however, reveals that an income guarantee scheme like NREGS can cause household debt to rise or fall, depending on the purpose and season, with an unclear net outcome in aggregate.

Second, where welfare analysis is concerned, an income guarantee scheme substitutes for borrowing to smooth consumption if the household does not cultivate. Even though the terms of credit may be onerous, the money-metric improvement in welfare from participating in the scheme will be less than the associated net income transfer if the household does borrow. The opposite holds if the household cultivates and participation leads to heavier borrowing to finance working capital. For the guarantee then induces the household to take up a riskier position, with a higher expected value of the resulting net pay-off. The scheme is then effectively a complement to borrowing. Calculating NREGS's effects on welfare is beyond the scope of this paper, but any such analysis needs to encompass how the scheme affects households' borrowing.

\section{Appendix}

If borrowers regard the policy represented by an increase in $\left(\eta_{1}, \eta_{2}, \eta_{3}\right)$ as permanent, then the resulting changes in the penalty incurred by defaulting, $V^{0}-V^{a}$, must be established before proceeding to the remaining steps in the comparative statics analysis.

By definition, $V^{a}$ is independent of $\xi_{3}^{d}$, since the associated decision simply does not arise. If $K_{2}>0, \xi_{3}^{d}$ becomes relevant; but $K_{2}$ is chosen optimally as part of the process that yields $V^{0}$, so that $\partial K_{2}^{0} / \partial \xi_{3}^{d}=0$ also. Hence, the question to be answered 
is whether $V^{0}-V^{a}$ is increasing or decreasing in $\eta_{3}$ without reference to $K_{2}$.

It is clear that both values are increasing in $\eta_{3}$; for consumption in season 3 will be greater in all states of nature for all $\left(K_{1}, K_{2}, \xi_{3}^{d}\right)$, including the no-borrowing case $(0,0, \cdot)$. Consider $V^{a}$ first.

$$
V^{a}=\sum_{\tau=0}^{\infty} \delta^{\tau} \cdot\left[E u\left(\xi_{1}(\tau)+\eta_{1}\right)+E u\left(\xi_{2}(\tau)+\eta_{2}\right)+E u\left(\xi_{3}(\tau)+\eta_{3}\right)\right] .
$$

We have

$$
\frac{\partial V^{a}}{\partial \eta_{3}}=\frac{\beta^{2} E u^{\prime}\left(\xi_{3}(\tau)+\eta_{3}\right)}{1-\delta}
$$

In deriving $V^{0}$, the branches arising from a positive probability of default must be incorporated. We have

$$
\begin{aligned}
V^{0} & =E u\left(\xi_{1}+\eta_{1}+K_{1}^{0}\left(\cdot, \eta_{3}\right)\right)+\beta E u\left(\xi_{2}+\eta_{1}+K_{2}^{0}\left(\cdot, \eta_{3}\right)-R K_{1}^{0}\left(\cdot, \eta_{3}\right)\right) \\
& +\beta^{2}\left(\int_{\xi_{3}^{1}}^{\xi_{3}^{d}} u\left(\xi_{3}+\eta_{3}\right) d F_{3}+\int_{\xi_{3}^{d}}^{\xi_{3}^{2}} u\left(\xi_{3}+\eta_{3}-R K_{2}^{0}\right) d F_{3}\right) \\
& +\delta p\left[E u\left(\xi_{1}+\eta_{1}+K_{1}^{0}\left(\cdot, \eta_{3}\right)\right)+\beta E u\left(\xi_{2}+\eta_{1}+K_{2}^{0}\left(\cdot, \eta_{3}\right)-R K_{1}^{0}\left(\cdot, \eta_{3}\right)\right)+\beta^{2}(\cdot)\right] \\
& +\delta^{2} p^{2}[\cdot]+\ldots+\left[(1-p) \delta V^{a}+(1-p) \delta^{2} p V^{a}+(1-p) \delta^{3} p^{2} V^{a}+\ldots\right] \\
& \equiv\left[\Omega+\delta(1-p) V^{a}\right] /(1-\delta p)>V^{a}
\end{aligned}
$$

where the inequality follows at once from the fact that on obtaining a loan, the borrower can always consume it and then default, and so do better than not borrowing at all.

Let $\eta_{3}$ increase. The borrower can always leave $\left(K_{1}, K_{2}, \xi_{3}^{d}\right)$ unchanged. This feasible action will leave $p$ unchanged, so that the only explicit argument of $\Omega$ that will change is $\eta_{3}$ itself. From (29),

$$
V^{0}-V^{a}=\left[\Omega+(1-\delta) V^{a}\right] /(1-\delta p)>0 .
$$

Now, the feasible action in question involves no change in $p$. Hence, recalling (28), we have

$$
\frac{\partial\left(V^{0}-V^{a}\right)}{\partial \eta_{3}}=\frac{1}{1-\delta p} \cdot\left(\frac{\partial \Omega}{\partial \eta_{3}}-\beta^{2} E u^{\prime}\left(\xi_{3}(\tau)+\eta_{3}\right)\right) .
$$


Consider, therefore, the only part of $\Omega$ that will vary, that is, the expression

$$
\beta^{2}\left(\int_{\xi_{3}^{1}}^{\xi_{3}^{d}} u\left(\xi_{3}+\eta_{3}\right) d F_{3}+\int_{\xi_{3}^{d}}^{\xi_{3}^{2}} u\left(\xi_{3}+\eta_{3}-R K_{2}^{0}\right) d F_{3}\right)
$$

Since, by hypothesis, $K_{1}$ and $K_{2}$ are left unchanged, we have

$$
\frac{\partial \Omega}{\partial \eta_{3}}=\beta^{2}\left(\int_{\xi_{3}^{1}}^{\xi_{3}^{d}} u^{\prime}\left(\xi_{3}+\eta_{3}\right) d F_{3}+\int_{\xi_{3}^{d}}^{\xi_{3}^{2}} u^{\prime}\left(\xi_{3}+\eta_{3}-R K_{2}^{0}\right) d F_{3}\right)>\beta^{2} E u^{\prime}\left(\xi_{3}+\eta_{3}\right)
$$

whenever $K_{2}>0$ in virtue of the strict concavity of $u$. It follows at once that $V^{0}-V^{a}$ is increasing in $\eta_{3}$.

To complete this preliminary step, observe that total differentiation of (4) yields

$$
\partial \xi_{3}^{d} / \partial K_{2}=-\frac{R u^{\prime}\left(\xi_{3}^{d}+\eta_{3}-R K_{2}\right)+\delta \cdot \partial\left(V^{0}-V^{a}\right) / \partial \eta_{3}}{u^{\prime}\left(\xi_{3}^{d}+\eta_{3}-R K_{2}\right)-u^{\prime}\left(\xi_{3}^{d}+\eta_{3}\right)}
$$

whose sign is the same as the expression in Section 2.1 when the changes in $\left(\eta_{1}, \eta_{2}, \eta_{3}\right)$ are confined to the current period. It is then straightforward to show that all of the comparative static results in Section 2 also hold in the setting in which the changes in $\left(\eta_{1}, \eta_{2}, \eta_{3}\right)$ are permanent. 


\section{References}

[1] Afridi, F., Iversen V., and Sharan M. R. (2013), 'Women political leaders, corruption and learning: Evidence from a large public program in India', IZA Discussion Paper 7212 and International Growth Centre (IGC) Working Paper.

[2] Azam, M. (2012), 'The Impact of Indian job guarantee scheme on labor market outcomes: Evidence from a natural experiment', IZA Discussion Paper 6548.

[3] Bardhan, P. (1983), 'Labor-tying in a poor agrarian economy: A theoretical and empirical analysis', The Quarterly Journal of Economics, 98(3): 501-514.

[4] Bardhan, P., Mookherjee, D., and Torrado M. P. (2010), 'Impact of political reservations in West Bengal local governments on anti-poverty targeting', Journal of Globalization and Development, 1(1): 1-36.

[5] Ban, R., and Rao V. (2008), 'Tokenism or agency? The impact of women's reservations on panchayats in south India', Economic Development and Cultural Change, 56: $501-530$.

[6] Basu, A.K. (2013), 'Impact of rural employment guarantee schemes on seasonal labor markets: Optimum compensation and workers' welfare', Journal of Economic Inequality, 11(1): 1-34.

[7] Bell, C., Srinivasan, T.N., and Udry, C. (1997), 'Rationing, spillover, and interlinking in credit markets: The case of rural Punjab', Oxford Economic Papers, 49(4): $557-585$.

[8] Besley, T., Montalvo J. G., and Reynal-Querol M. (2011), 'Do Educated Leaders Matter?', The Economic Journal, 121(554): 205-227.

[9] Chattopadhyay, R., and Duflo E. (2004), 'Women as policy makers: Evidence from a randomized policy experiment in India', Econometrica, 72(5): 1409-43. 
[10] Dey, S., and Imai K. (2014), 'Workfare as collateral: The case of National Rural Employment Guarantee Scheme (NREGS) of India', Economic Discussion Paper No. 1412, Economics Department, University of Manchester.

[11] Gehrke, E. (2014), 'An employment guarantee at risk insurance? Assessing the effects of the NREGS on agricultural production decisions', BGPE Discussion Paper No. 152.

[12] Hatlebakk, M. (2009), 'Capacity-constrained collusive price discrimination in the informal rural credit markets of Nepal', Review of Development Economics, 13(1): $70-86$.

[13] Imbert, C., and Papp J. (2015), Labor market effects of social programs: Evidence from India's employment guarantee', American Economic Journal: Applied Economics, 7(2): 233-63.

[14] Klonner, S., and Oldiges C. (2014), 'Safety net for India's poor or waste of public funds? Poverty and welfare in the wake of the world's largest job guarantee program', AWI Discussion Paper Series No. 564, University of Heidelberg.

[15] McManus, J. (2014), 'Educational qualifications of village leaders in north India: Implications for public service delivery, mimeo, Harvard University.

[16] Raghunathan, K., and Fields, G. (2014), 'For better or for worse? The effects of an employment guarantee in a seasonal agricultural market', mimeo, Cornell University.

[17] Raghunathan K., and Hari S. (2014), 'Providing more than just employment? Evidence from the NREGA in India', mimeo, Cornell University.

[18] Rajaraman I., and Gupta, M. (2012), 'Public expenditure choices and gender quotas', Indian Growth and Development Review, 5(2): 108-130.

[19] Saraswat, D. (2011), 'Effect of employment guarantee on access to credit: Evidence from rural India', MPRA Paper No. 34671. 
[20] van Dillen, S. (2008), 'Income and its variability in a drought-prone region: Seasonality, location and household characteristics', European Journal of Development Research, 20(4): 579-596.

[21] Zimmermann, L. (2014), 'Why guarantee employment? Evidence from a large Indian public-works program', mimeo, University of Georgia. 


\section{Figure 1: Monthwise Total Number of Loans Taken}

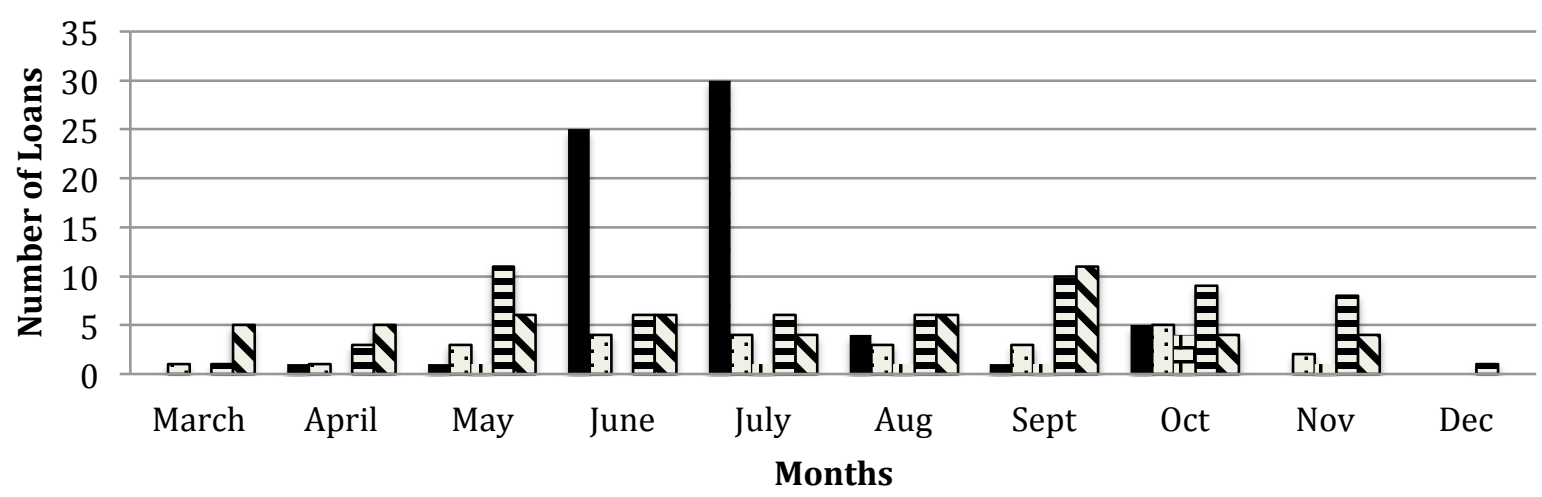

- Agricultural Inputs $\square$ Consumption I Funeral

$\Xi$ Medical Expenditures $\mathbf{\Delta}$ Other Purposes

Figure 2: Monthly Distribution of NREGS Payments

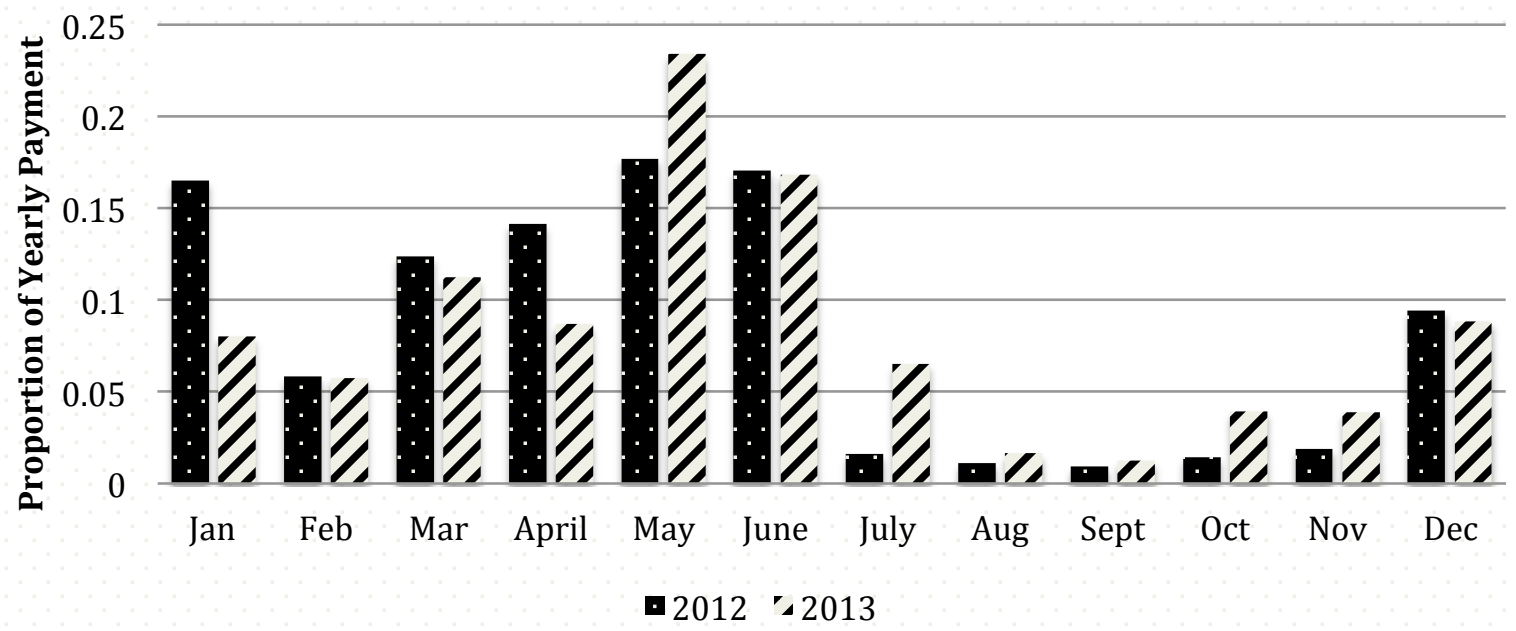


Table 1: Summary Statistics

\begin{tabular}{|c|c|c|c|}
\hline Variable & Obs & Mean & Std. Dev. \\
\hline Household has taken loan: yes $=1,0$ otherwise & 279 & .43 & .5 \\
\hline Total amount of loan (Rs.) & 279 & 5105.81 & 9598.95 \\
\hline Household has taken a consumption loan: yes $=1,0$ otherwise & 279 & .27 & .44 \\
\hline Total amount of consumption loan (Rs.) & 279 & 2215.05 & 5989.68 \\
\hline Household has taken a production loan: yes $=1,0$ otherwise & 279 & .22 & .41 \\
\hline Total amount of production loan (Rs.) & 279 & 2890.76 & 7494.14 \\
\hline Household has participated in NREGS: yes $=1,0$ otherwise & 279 & .29 & .45 \\
\hline Number of days the household has worked on NREGS in the year & 279 & 14.29 & 32.85 \\
\hline Household belongs to General or Scheduled Caste & 279 & .37 & .48 \\
\hline Household belongs to Scheduled Tribe & 279 & .19 & .39 \\
\hline Household belongs to Other Backward Castes & 279 & .44 & .5 \\
\hline Land owned (in acres) & 279 & 1.99 & 2.13 \\
\hline Household has a Below Poverty Line Card & 279 & .7 & .46 \\
\hline Household size & 279 & 4.97 & 2.01 \\
\hline Proportion of adults $(20+)$ who are male & 279 & .3 & .17 \\
\hline Average age of household members & 279 & 31.67 & 12.33 \\
\hline Years of education for the most educated person in the household & 279 & 5.88 & 4.03 \\
\hline Total number of episodes of morbidity in the household (Jan-Dec) & 279 & 2.22 & 1.94 \\
\hline Total number of deaths in the household (Jan-Dec) & 279 & .03 & .16 \\
\hline Total number of households registered for NREGS work & 279 & 137.52 & 87.18 \\
\hline Village development Index Quartile: 4 (most developed) & 279 & .26 & .44 \\
\hline Village development Index Quartile: 3 & 279 & .25 & .44 \\
\hline Village development Index Quartile: 2 & 279 & .26 & .44 \\
\hline Village development Index Quartile: 1 (least developed) & 279 & .23 & .42 \\
\hline Total village area (acres) & 279 & 291 & 144.5 \\
\hline Proportion of village land irrigated & 279 & .04 & .06 \\
\hline Distance to district centre (kms.) & 279 & 71.87 & 28 \\
\hline Distance to block centre (kms.) & 279 & 14.37 & 7.24 \\
\hline Distance to panchayat office (kms.) & 279 & 3.81 & 1.91 \\
\hline Distance to closest bank (kms.) & 279 & 9.3 & 3.87 \\
\hline Distance to closest cooperative society (kms.) & 279 & 5.15 & 2.96 \\
\hline Village has a self help group, yes $=1,0$ otherwise & 279 & .78 & .41 \\
\hline Credit Market Competition: competitive $=1,0$ otherwise & 279 & .82 & .38 \\
\hline Education of the sarpanch (yrs) & 279 & 9.41 & 3.31 \\
\hline Sarpanch seat is reserved for a woman & 279 & .29 & .45 \\
\hline
\end{tabular}


Table 2: Summary Statistics by NREGS participation

\begin{tabular}{|c|c|c|c|c|c|}
\hline \multirow[t]{2}{*}{ Variable } & \multicolumn{2}{|c|}{ NREGS $(A)$} & \multicolumn{2}{|c|}{ "Non NREGS $(B)$} & \multirow{2}{*}{$\frac{\text { Two sided } t \text { Test }}{A-B}$} \\
\hline & Mean & Std. Dev. & Mean & Std. Dev. & \\
\hline Household has taken loan: yes $=1,0$ otherwise & .44 & .5 & .42 & .49 & .025 \\
\hline Total amount of loan (Rs.) & 4435 & 7461 & 5380 & 10351 & -945 \\
\hline Household has taken a consumption loan: yes $=1,0$ otherwise & .23 & .43 & .28 & .45 & -.05 \\
\hline Total amount of consumption loan (Rs.) & 981 & 2366 & 2720 & 6890 & $-1738^{* *}$ \\
\hline Household has taken a production loan: yes $=1,0$ otherwise & .26 & .44 & .2 & .4 & .06 \\
\hline Total amount of production loan (Rs.) & 3453 & 7261 & 2661 & 7593 & 792 \\
\hline Household has participated in NREGS: yes $=1,0$ otherwise & 1 & 0 & 0 & 0 & . \\
\hline Number of days the household has worked on NREGS in the year & 49.23 & 44.81 & 0 & 0 & $49.23^{* * *}$ \\
\hline Household belongs to General or Scheduled Caste & .3 & .46 & .4 & .49 & $-.10^{*}$ \\
\hline Household belongs to Scheduled Tribe & .09 & .28 & .23 & .42 & $-.14^{* * *}$ \\
\hline Household belongs to Other Backward Castes & .62 & .49 & .37 & .48 & $.25^{* * *}$ \\
\hline Land owned (in acres) & 2.12 & 2.14 & 1.93 & 2.13 & .19 \\
\hline Household has a Below Poverty Line Card & .78 & .42 & .67 & .47 & $.11^{*}$ \\
\hline Household size & 5.32 & 2.26 & 4.83 & 1.89 & $.49^{*}$ \\
\hline Proportion of adults $(20+)$ who are male & .33 & .18 & .29 & .17 & $.04^{*}$ \\
\hline Average age of household members & 29.77 & 10.21 & 32.44 & 13.04 & $-2.68^{*}$ \\
\hline Years of education for the most educated person in the household & 6.33 & 3.66 & 5.69 & 4.17 & .64 \\
\hline Total number of episodes of morbidity in the household (Jan-Dec) & 2.41 & 2 & 2.14 & 1.92 & .27 \\
\hline Total number of deaths in the household (Jan-Dec) & .01 & .11 & .03 & .17 & -.02 \\
\hline Total number of households registered for NREGS work & 124 & 80 & 143 & 90 & $-19^{*}$ \\
\hline Village development Index Quartile: 4 (most developed) & .21 & .41 & .28 & .45 & -.07 \\
\hline Village development Index Quartile: 3 & .23 & .43 & .26 & .44 & -.03 \\
\hline Village development Index Quartile: 2 & .35 & .48 & .22 & .42 & $.12^{* *}$ \\
\hline Village development Index Quartile: 1 (least developed) & .21 & .41 & .24 & .43 & -.03 \\
\hline Total village area (in acres) & 284 & 10.41 & 306 & 15.65 & -22 \\
\hline Proportion of village land irrigated & .05 & .06 & .04 & .06 & 0.01 \\
\hline Distance to district centre (kms.) & 69.35 & 28.75 & 72.91 & 27.7 & -3.56 \\
\hline Distance to block centre (kms.) & 16 & 8.02 & 13.71 & 6.8 & $2.29^{* *}$ \\
\hline Distance to panchayat office (kms.) & 4.09 & 1.94 & 3.69 & 1.89 & .39 \\
\hline Distance to closest bank (kms.) & 8.78 & 3.06 & 9.52 & 4.14 & -.74 \\
\hline Distance to closest cooperative society (kms.) & 5.35 & 3.03 & 5.08 & 2.93 & .27 \\
\hline Village has a self help group, yes $=1,0$ otherwise & .88 & .33 & .74 & .44 & $.13^{* *}$ \\
\hline Credit Market Competition: competitive $=1,0$ otherwise & .78 & .42 & .84 & .37 & .06 \\
\hline Education of the sarpanch (yrs) & 9.26 & 2.77 & 9.47 & 3.51 & -.21 \\
\hline Sarpanch seat is reserved for a woman & .2 & .4 & .32 & .47 & $-.12^{* *}$ \\
\hline Number of Observations & 81 & & 198 & & \\
\hline
\end{tabular}




\begin{tabular}{|c|c|c|c|c|c|c|}
\hline \multirow[b]{2}{*}{ VARIABLES } & \multicolumn{3}{|c|}{ OLS } & \multicolumn{3}{|c|}{ Instrumental Variable } \\
\hline & $\begin{array}{l}(1) \\
L^{A}\end{array}$ & $\begin{array}{l}(2) \\
L^{C}\end{array}$ & $\begin{array}{l}(3) \\
L^{P} \\
\end{array}$ & $\begin{array}{l}(4) \\
L^{A} \\
\end{array}$ & $\begin{array}{l}(5) \\
L^{C}\end{array}$ & $\begin{array}{l}(6) \\
L^{P}\end{array}$ \\
\hline Household has participated in NREGS: yes $=1,0$ otherwise & $\begin{array}{l}-0.03 \\
(0.08)\end{array}$ & $\begin{array}{l}-0.04 \\
(0.07)\end{array}$ & $\begin{array}{l}-0.02 \\
(0.07)\end{array}$ & $\begin{array}{c}0.18 \\
(0.31)\end{array}$ & $\begin{array}{c}-0.25^{*} \\
(0.14)\end{array}$ & $\begin{array}{c}0.60^{*} \\
(0.32)\end{array}$ \\
\hline Household belongs to Scheduled Tribe & $\begin{array}{c}-0.01 \\
(0.09)\end{array}$ & $\begin{array}{c}0.02 \\
(0.09)\end{array}$ & $\begin{array}{l}-0.02 \\
(0.07)\end{array}$ & $\begin{array}{c}0.01 \\
(0.09)\end{array}$ & $\begin{array}{l}-0.00 \\
(0.08)\end{array}$ & $\begin{array}{c}0.05 \\
(0.09)\end{array}$ \\
\hline Household belongs to Other Backward Castes & $\begin{array}{l}-0.02 \\
(0.08)\end{array}$ & $\begin{array}{l}-0.09 \\
(0.06)\end{array}$ & $\begin{array}{c}0.05 \\
(0.08)\end{array}$ & $\begin{array}{l}-0.04 \\
(0.08)\end{array}$ & $\begin{array}{l}-0.07 \\
(0.07)\end{array}$ & $\begin{array}{l}-0.02 \\
(0.08)\end{array}$ \\
\hline Proportion of adults $(20+)$ who are male & $\begin{array}{c}-0.02 \\
(0.20)\end{array}$ & $\begin{array}{c}-0.03 \\
(0.18)\end{array}$ & $\begin{array}{l}-0.00 \\
(0.15)\end{array}$ & $\begin{array}{l}-0.08 \\
(0.21)\end{array}$ & $\begin{array}{c}0.04 \\
(0.17)\end{array}$ & $\begin{array}{l}-0.20 \\
(0.21)\end{array}$ \\
\hline Land owned (in acres) & $\begin{array}{c}0.00 \\
(0.02)\end{array}$ & $\begin{array}{l}-0.01 \\
(0.01)\end{array}$ & $\begin{array}{c}0.01 \\
(0.02)\end{array}$ & $\begin{array}{c}0.01 \\
(0.02)\end{array}$ & $\begin{array}{l}-0.01 \\
(0.01)\end{array}$ & $\begin{array}{c}0.03 \\
(0.02)\end{array}$ \\
\hline Household has a Below Poverty Line Card & $\begin{array}{l}-0.01 \\
(0.07)\end{array}$ & $\begin{array}{l}-0.06 \\
(0.07)\end{array}$ & $\begin{array}{c}0.03 \\
(0.06)\end{array}$ & $\begin{array}{c}-0.02 \\
(0.07)\end{array}$ & $\begin{array}{l}-0.04 \\
(0.07)\end{array}$ & $\begin{array}{l}-0.02 \\
(0.07)\end{array}$ \\
\hline Household size & $\begin{array}{c}0.02 \\
(0.01)\end{array}$ & $\begin{array}{c}0.00 \\
(0.01)\end{array}$ & $\begin{array}{c}0.02 \\
(0.01)\end{array}$ & $\begin{array}{c}0.02 \\
(0.02)\end{array}$ & $\begin{array}{c}0.01 \\
(0.01)\end{array}$ & $\begin{array}{c}0.00 \\
(0.01)\end{array}$ \\
\hline Average age of household members & $\begin{array}{l}-0.00 \\
(0.00)\end{array}$ & $\begin{array}{l}-0.00 \\
(0.00)\end{array}$ & $\begin{array}{l}-0.00 \\
(0.00)\end{array}$ & $\begin{array}{l}-0.00 \\
(0.00)\end{array}$ & $\begin{array}{c}-0.00^{*} \\
(0.00)\end{array}$ & $\begin{array}{l}-0.00 \\
(0.00)\end{array}$ \\
\hline Years of education for the most educated person in the household & $\begin{array}{c}-0.01^{*} \\
(0.01)\end{array}$ & $\begin{array}{c}-0.01^{*} \\
(0.01)\end{array}$ & $\begin{array}{l}-0.01 \\
(0.01)\end{array}$ & $\begin{array}{c}-0.01^{* *} \\
(0.01)\end{array}$ & $\begin{array}{c}-0.01^{*} \\
(0.01)\end{array}$ & $\begin{array}{l}-0.01 \\
(0.01)\end{array}$ \\
\hline Total number of episodes of morbidity in the household (Jan-Dec) & $\begin{array}{c}0.05 * * * \\
(0.02)\end{array}$ & $\begin{array}{c}0.05^{* * *} \\
(0.01)\end{array}$ & $\begin{array}{l}0.03^{*} \\
(0.01)\end{array}$ & $\begin{array}{c}0.05^{* * *} \\
(0.02)\end{array}$ & $\begin{array}{c}0.05^{* * *} \\
(0.01)\end{array}$ & $\begin{array}{c}0.02 \\
(0.02)\end{array}$ \\
\hline Total number of deaths in the household (Jan-Dec) & $\begin{array}{c}0.44^{* * *} \\
(0.15)\end{array}$ & $\begin{array}{c}0.48^{* *} \\
(0.21)\end{array}$ & $\begin{array}{c}0.17 \\
(0.16)\end{array}$ & $\begin{array}{c}0.47 * * * \\
(0.16)\end{array}$ & $\begin{array}{c}0.45^{* *} \\
(0.19)\end{array}$ & $\begin{array}{c}0.27 \\
(0.19)\end{array}$ \\
\hline Total number of households registered for NREGS work & $\begin{array}{l}-0.00 \\
(0.00)\end{array}$ & $\begin{array}{c}0.00 \\
(0.00)\end{array}$ & $\begin{array}{c}-0.00^{* *} \\
(0.00)\end{array}$ & $\begin{array}{l}-0.00 \\
(0.00)\end{array}$ & $\begin{array}{c}0.00 \\
(0.00)\end{array}$ & $\begin{array}{c}-0.00^{* * *} \\
(0.00)\end{array}$ \\
\hline Village development Index Quartile: 4 (most developed) & $\begin{array}{c}0.09 \\
(0.28)\end{array}$ & $\begin{array}{c}0.07 \\
(0.15)\end{array}$ & $\begin{array}{l}-0.10 \\
(0.25)\end{array}$ & $\begin{array}{c}0.03 \\
(0.24)\end{array}$ & $\begin{array}{c}0.13 \\
(0.18)\end{array}$ & $\begin{array}{l}-0.26 \\
(0.21)\end{array}$ \\
\hline Village development Index Quartile: 3 & $\begin{array}{c}0.07 \\
(0.18)\end{array}$ & $\begin{array}{c}0.02 \\
(0.10)\end{array}$ & $\begin{array}{c}0.05 \\
(0.19)\end{array}$ & $\begin{array}{c}0.02 \\
(0.18)\end{array}$ & $\begin{array}{c}0.06 \\
(0.11)\end{array}$ & $\begin{array}{l}-0.08 \\
(0.20)\end{array}$ \\
\hline Village development Index Quartile: 2 & $\begin{array}{c}0.21 \\
(0.14)\end{array}$ & $\begin{array}{c}0.20^{* *} \\
(0.07)\end{array}$ & $\begin{array}{c}0.10 \\
(0.14)\end{array}$ & $\begin{array}{c}0.15 \\
(0.17)\end{array}$ & $\begin{array}{c}0.25 * * * \\
(0.08)\end{array}$ & $\begin{array}{l}-0.05 \\
(0.17)\end{array}$ \\
\hline Total village area (2013) & $\begin{array}{c}-0.18 \\
(0.35)\end{array}$ & $\begin{array}{l}-0.21 \\
(0.21)\end{array}$ & $\begin{array}{l}-0.16 \\
(0.31)\end{array}$ & $\begin{array}{l}-0.18 \\
(0.35)\end{array}$ & $\begin{array}{l}-0.15 \\
(0.21)\end{array}$ & $\begin{array}{l}-0.30 \\
(0.48)\end{array}$ \\
\hline Proportion of village land irrigated & $\begin{array}{l}-0.75 \\
(0.86)\end{array}$ & $\begin{array}{c}-0.68 \\
(0.49)\end{array}$ & $\begin{array}{l}-0.35 \\
(0.90)\end{array}$ & $\begin{array}{c}-0.70 \\
(0.76)\end{array}$ & $\begin{array}{l}-0.63 \\
(0.54)\end{array}$ & $\begin{array}{c}-0.45 \\
(0.89)\end{array}$ \\
\hline Education of the sarpanch (yrs) & $\begin{array}{l}-0.00 \\
(0.02)\end{array}$ & $\begin{array}{c}0.01 \\
(0.01)\end{array}$ & $\begin{array}{l}-0.01 \\
(0.01)\end{array}$ & $\begin{array}{l}-0.00 \\
(0.02)\end{array}$ & $\begin{array}{c}0.01 \\
(0.01)\end{array}$ & $\begin{array}{c}-0.02^{*} \\
(0.01)\end{array}$ \\
\hline Distance to district centre (kms.) & $\begin{array}{c}0.00 \\
(0.00)\end{array}$ & $\begin{array}{c}0.00 \\
(0.00)\end{array}$ & $\begin{array}{c}0.00 \\
(0.00)\end{array}$ & $\begin{array}{l}-0.00 \\
(0.00)\end{array}$ & $\begin{array}{c}0.00 \\
(0.00)\end{array}$ & $\begin{array}{c}-0.01 \\
(0.00)\end{array}$ \\
\hline Distance to panchayat office (kms.) & $\begin{array}{c}0.02 \\
(0.03)\end{array}$ & $\begin{array}{c}0.02 \\
(0.01)\end{array}$ & $\begin{array}{l}-0.02 \\
(0.02)\end{array}$ & $\begin{array}{c}0.01 \\
(0.03)\end{array}$ & $\begin{array}{l}0.03^{*} \\
(0.01)\end{array}$ & $\begin{array}{c}-0.04 \\
(0.03)\end{array}$ \\
\hline Distance to block centre (kms.) & $\begin{array}{c}-0.01 \\
(0.01)\end{array}$ & $\begin{array}{c}-0.01^{*} \\
(0.00)\end{array}$ & $\begin{array}{l}-0.00 \\
(0.01)\end{array}$ & $\begin{array}{l}-0.01 \\
(0.01)\end{array}$ & $\begin{array}{c}-0.01^{* *} \\
(0.00)\end{array}$ & $\begin{array}{c}0.00 \\
(0.01)\end{array}$ \\
\hline Distance to closest bank (kms.) & $\begin{array}{l}-0.00 \\
(0.01)\end{array}$ & $\begin{array}{c}0.00 \\
(0.01)\end{array}$ & $\begin{array}{l}-0.01 \\
(0.01)\end{array}$ & $\begin{array}{c}-0.00 \\
(0.01)\end{array}$ & $\begin{array}{c}0.00 \\
(0.01)\end{array}$ & $\begin{array}{l}-0.00 \\
(0.01)\end{array}$ \\
\hline Distance to closest cooperative society (kms.) & $\begin{array}{c}0.02 \\
(0.02)\end{array}$ & $\begin{array}{c}0.00 \\
(0.01)\end{array}$ & $\begin{array}{c}0.01 \\
(0.02)\end{array}$ & $\begin{array}{c}0.01 \\
(0.02)\end{array}$ & $\begin{array}{c}0.01 \\
(0.01)\end{array}$ & $\begin{array}{c}0.00 \\
(0.02)\end{array}$ \\
\hline Village has a self help group, yes $=1,0$ otherwise & $\begin{array}{c}0.05 \\
(0.08)\end{array}$ & $\begin{array}{c}0.06 \\
(0.06)\end{array}$ & $\begin{array}{c}0.05 \\
(0.07)\end{array}$ & $\begin{array}{c}0.01 \\
(0.12)\end{array}$ & $\begin{array}{c}0.12^{* *} \\
(0.05)\end{array}$ & $\begin{array}{l}-0.10 \\
(0.12)\end{array}$ \\
\hline Credit Market Competition: competitive $=1,0$ otherwise & $\begin{array}{l}-0.05 \\
(0.13)\end{array}$ & $\begin{array}{l}-0.05 \\
(0.09)\end{array}$ & $\begin{array}{l}-0.01 \\
(0.13)\end{array}$ & $\begin{array}{l}-0.02 \\
(0.14)\end{array}$ & $\begin{array}{l}-0.09 \\
(0.07)\end{array}$ & $\begin{array}{c}0.09 \\
(0.16)\end{array}$ \\
\hline Constant & $\begin{array}{c}0.20 \\
(0.95)\end{array}$ & $\begin{array}{c}0.25 \\
(0.58)\end{array}$ & $\begin{array}{c}0.28 \\
(0.85)\end{array}$ & $\begin{array}{c}0.56 \\
(0.93)\end{array}$ & $\begin{array}{l}-0.12 \\
(0.68)\end{array}$ & $\begin{array}{c}1.37 \\
(0.91)\end{array}$ \\
\hline Block Fixed Effects & YES & YES & YES & YES & YES & YES \\
\hline Observations & 279 & 279 & 279 & 279 & 279 & 279 \\
\hline R-squared & 0.174 & 0.168 & 0.180 & & & \\
\hline
\end{tabular}

First Stage: Sarpanch seat is reserved for a woman $\quad-.39^{* * *}$

F stat $14.65^{* * *}$

Kleibergen-Paap rk Wald F statistic 
Table 4: Amount Borrowed (Rs.)

\begin{tabular}{ccc} 
& \multicolumn{2}{c}{ IV Tobit } \\
\cline { 2 - 3 } & $(1)$ & $(2)$ \\
\hline VARIABLE & $K^{C}$ & $K^{P}$ \\
Number of days the household has worked on NREGS in the year & $-273^{*}$ & $963^{* *}$ \\
& $(141.6)$ & $(387.06)$ \\
All other Covariates & YES & YES \\
\hline \hline Number of observations & 279 & 279 \\
Number of censored observations & 204 & 218 \\
Wald Test of Exogeneity & 2.57 & $5.99^{* *}$ \\
\hline \hline First Stage & \multicolumn{2}{c}{$-23.6^{* * *}$} \\
\hline \hline Sarpanch seat is reserved for a woman & $-73^{*}$ & $277^{* *}$ \\
\hline Marginal Effect conditional on $K^{j}>0$ &
\end{tabular}

\begin{tabular}{|c|c|c|c|c|}
\hline \multicolumn{5}{|l|}{ Table 5: Seasonal Effects } \\
\hline & \multicolumn{2}{|c|}{ IV -LPM } & \multicolumn{2}{|c|}{ IV Tobit } \\
\hline & $(1)$ & $(2)$ & $(3)$ & $(4)$ \\
\hline VARIABLE & \multicolumn{2}{|c|}{$L$} & \multicolumn{2}{|c|}{$K$} \\
\hline & $L_{1}$ & $L_{2}$ & $K_{1}$ & $K_{2}$ \\
\hline Household has participated in NREGS: yes $=1,0$ otherwise & $-.19^{* *}$ & .61 & & \\
\hline & $(.08)$ & $(.42)$ & & \\
\hline Number of days the household has worked on NREGS in the year & & & $-1421^{* *}$ & $442.2^{*}$ \\
\hline & & & $(574)$ & $(250)$ \\
\hline All other Covariates $\#$ & YES & YES & YES & YES \\
\hline Number of observations & 279 & 279 & 279 & 279 \\
\hline Number of censored observations & & & 253 & 184 \\
\hline Marginal Effect conditional on $K_{i}>0$ & & & $-373^{* *}$ & $138^{*}$ \\
\hline
\end{tabular}

in the rabi season to measure morbidity. Robust clustered standard errors in parentheses $* * * \mathrm{p}<0.01,{ }^{* *} \mathrm{p}<0.05, * \mathrm{p}<0.1$

\section{Table 6: Robustness}
(1)
(2)
(3)
(4)
(5)
(6)

\section{VARIABLES}

Household has participated in NREGS: yes $=1,0$ otherwise

\begin{tabular}{ccccccc}
$-0.25^{*}$ & $-0.26^{* *}$ & $-0.26^{*}$ & $-0.26^{* * *}$ & $0.61^{*}$ & $0.61^{*}$ & $0.69^{*}$ \\
$(0.14)$ & $(0.12)$ & $(0.15)$ & $(0.08)$ & $(0.34)$ & $(0.34)$ & $(0.36)$ \\
YES & & & \multicolumn{3}{c}{ YES } &
\end{tabular}

Baseline

Outstanding Loan

Distance to nearest All Weather Road

Expenditure on Other Schemes
YES
YES

YES

\section{YES}

\begin{tabular}{|c|c|c|c|c|c|c|c|c|}
\hline Expenditure on Other Schemes & & & & YES & & & & YES \\
\hline Number of observations & 279 & 279 & 279 & 251 & 279 & 279 & 279 & 251 \\
\hline
\end{tabular}

Robust clustered standard errors in parentheses ${ }^{* * *} \mathrm{p}<0.01,{ }^{* *} \mathrm{p}<0.05,{ }^{*} \mathrm{p}<0.1$ 
Table A.1: Village Level NREGS (2013)

(1)

$(2)$

(3)

(4)

VARIABLES

\# of NREGS HH.s \# of NREGS HH.s \# of NREGS HH.s \# of NREGS HH.s

Sarpanch seat is reserved for a woman

$\begin{array}{lc}-32.746 & -49.165^{* *} \\ (20.607) & (19.129)\end{array}$

Sarpanch seat is reserved for a Scheduled Caste

$(19.129)$

Sarpanch seat is reserved for a Scheduled Tribe

Village Development Index

Total number of households registered for NREGS work

Rainfall Deviation (2013) from long run average

Constant

\section{$56.190^{* * *}$}

(11.287)

-5.443
$(4.584)$
$0.308^{* * *}$
$(0.102)$
0.598
$(0.790)$
29.295
$(20.806)$

-15.489
$(25.716)$
-20.925
$(24.015)$
-3.052
$(5.286)$
$0.226^{*}$
$(0.112)$
0.528
$(0.917)$
32.486
$(25.431)$

$-51.166^{* *}$

(21.339)

$-17.643$

(23.513)

$-0.496$

$(23.538)$
-5.072

(4.903)

$0.311^{* * *}$

(0.108)

0.452

(0.838)

30.771

(23.247)

$\begin{array}{llll}\text { Observations } & 30 & 30 & 30\end{array}$

$\begin{array}{lc}\text { R-squared } & 30 \\ & \text { Standard errors in parentheses }\end{array}$

Standard errors in parentheses

Table A.2:Village Level NREGS(2013)

\section{VARIABLES}

\section{(1) (2)}

(3)

0.363

\section{Sarpanch seat is reserved for a woman}

Sarpanch seat is reserved for a Scheduled Caste

Sarpanch seat is reserved for a Scheduled Tribe

Village Development Index

Total number of households registered for NREGS work

Rainfall Deviation (2013) from long run average

Constant

Observations

R-squared \# of NREGS Persondays \# of NREGS Persondays \# of NREGS Persondays

$\begin{array}{cc}-985.540 & -1,532.623^{*} \\ (877.503) & (866.192)\end{array}$

$(866.192)$

-332.353
$(207.551)$
$10.090^{* *}$
$(4.625)$
-6.732
$(35.752)$
996.583
$(942.107)$

-58.641
$(1,118.619)$
84.604
$(1,044.647)$
-296.617
$(229.943)$
7.951
$(4.860)$
-9.445
$(39.891)$
773.578
$(1,106.262)$

$-1,843.814^{*}$ (963.940)

$-136.264$

$(1,062.148)$ 820.787

$(1,063.286)$

$-369.403$

(221.469)

$10.994^{* *}$

(4.878)

$-12.181$

(37.876)

711.788

$(1,050.145)$

30

$0.229 \quad 0.133$

30

0.043

Standard errors in parentheses
$* * * \mathrm{p}<0.01, * * \mathrm{p}<0.05, * \mathrm{p}<0.1$

0.252 
Table A.3: Summary Statistics by Female Reservation

\begin{tabular}{|c|c|c|c|c|c|}
\hline \multirow[t]{2}{*}{ Variable } & \multicolumn{2}{|c|}{ Fem Res. $(A)$} & \multicolumn{2}{|c|}{ Not Fem Res. $(B)$} & \multirow{2}{*}{$\begin{array}{c}\text { Two sided } t \text { Test } \\
A-B\end{array}$} \\
\hline & Mean & Std. Dev. & Mean & Std. Dev. & \\
\hline Household has taken loan: yes $=1,0$ otherwise & .49 & .5 & .4 & .49 & .09 \\
\hline Total amount of loan (Rs.) & 5590 & 9792 & 4911 & 9538 & 678 \\
\hline Household has taken a consumption loan: yes $=1,0$ otherwise & .35 & .48 & .24 & .43 & $.11^{*}$ \\
\hline Total amount of consumption loan (Rs.) & 2388 & 5044 & 2146 & 6341 & 242 \\
\hline Household has taken a production loan: yes $=1,0$ otherwise & .2 & .4 & .23 & .42 & -.03 \\
\hline Total amount of production loan (Rs.) & 3203 & 8612 & 2765 & 7015 & 437 \\
\hline Household has participated in NREGS: yes $=1,0$ otherwise & .2 & .4 & .33 & .47 & $-.13^{* *}$ \\
\hline Number of days the household has worked on NREGS in the year & 11.05 & 31.29 & 15.6 & 33.44 & -4.54 \\
\hline Household belongs to General or Scheduled Caste & .34 & .48 & .39 & .49 & -.05 \\
\hline Household belongs to Scheduled Tribe & .16 & .37 & .2 & .4 & -.03 \\
\hline Household belongs to Other Backward Castes & .5 & .5 & .42 & .49 & 0.08 \\
\hline Land owned (in acres) & 1.88 & 2.21 & 2.03 & 2.1 & -.15 \\
\hline Household has a Below Poverty Line Card & .66 & .48 & .72 & .45 & -.06 \\
\hline Household size & 4.9 & 1.97 & 5 & 2.04 & -.1 \\
\hline Proportion of adults $(20+)$ who are male & .26 & .15 & .31 & .18 & $-.06^{* *}$ \\
\hline Average age of household members & 30.59 & 12.71 & 32.1 & 12.17 & -1.5 \\
\hline Years of education for the most educated person in the household & 4.55 & 3.96 & 6.41 & 3.95 & $-1.86^{* * *}$ \\
\hline Total number of episodes of morbidity in the household (Jan-Dec) & 2.34 & 2.08 & 2.17 & 1.89 & .16 \\
\hline Total number of deaths in the household (Jan-Dec) & .01 & .11 & .03 & .17 & -.02 \\
\hline Total number of households registered for NREGS work & 166 & 96.09 & 126 & 80.81 & $39.86^{* * *}$ \\
\hline Village development Index Quartile: 4 (most developed) & .3 & .46 & .24 & .43 & .06 \\
\hline Village development Index Quartile: 3 & 0 & 0 & .36 & .48 & $-.36^{* * *}$ \\
\hline Village development Index Quartile: 2 & .34 & .48 & .23 & .42 & $.11^{*}$ \\
\hline Village development Index Quartile: 1 (least developed) & .36 & .48 & .18 & .38 & $.19^{* * *}$ \\
\hline Total village area (acres) & 348 & 12.66 & 268 & 10.8 & $80^{* * *}$ \\
\hline Proportion of village land irrigated & .04 & .05 & .04 & .06 & -.0002 \\
\hline Distance to district centre (kms.) & 82.26 & 27.19 & 67.7 & 27.29 & $14.56^{* * *}$ \\
\hline Distance to block centre (kms.) & 15.46 & 8.82 & 13.93 & 6.47 & 1.53 \\
\hline Distance to panchayat office (kms.) & 4.31 & 2.27 & 3.6 & 1.7 & $.71^{* * *}$ \\
\hline Distance to closest bank (kms.) & 9.95 & 3.17 & 9.05 & 4.09 & $.9^{*}$ \\
\hline Distance to closest cooperative society (kms.) & 6.28 & 3.68 & 4.7 & 2.48 & $1.57^{* * *}$ \\
\hline Village has a self help group, yes $=1,0$ otherwise & .9 & .3 & .73 & .44 & $.16^{* * *}$ \\
\hline Credit Market Competition: competitive $=1,0$ otherwise & .69 & .47 & .87 & .33 & $-.19^{* * *}$ \\
\hline Education of the sarpanch (yrs) & 6.05 & 2.79 & 10.76 & 2.43 & $-4.71^{* * *}$ \\
\hline Number of Observations & 80 & & 199 & & \\
\hline
\end{tabular}

